\title{
Prácticas criollas y liberalismo en la crisis del espacio urbano colonial. El 29 de noviembre de 1812 en la ciudad de México*
}

Antonio Annino UNIVERSIDAD DE FLORENCIA

a imagen más común del proceso electoral en la América Latina del siglo XIX está condicionada por un arquetipo: el poder disciplinario de la gran propiedad terrateniente. La literatura y la historiografía se han familiarizado con la idea de que las articulaciones fundamentales de la política latinoamericana del siglo XIX se encuentran en la estructura de dominio de los espacios rurales y en su continuidad sustancial con respecto a la época colonial. Sin embargo, esta visión tiende a minimizar el hecho de que el dominio político de la gran hacienda no fue el resultado inevitable de su peso económico, sino de las revoluciones liberales de la mitad del siglo. Para liberar a la hacienda de los vínculos y de la subordinación a su pasado colonial, fueron necesarias repetidas

* Publicado en Quaderni Storici, vol. 69, año xxill, núm. 3, diciembre de 1988, pp. 727763. Traducción de Gabriela Montes de Oca. Forma parte de una investigación más amplia, parcialmente financiada por la Secretaría de Educación Pública de México sobre las "Formas históricas del Estado en América Latina". El auror desea agradecer la amabilidad del personal del Archivo General de la Nación de México en su auxilio para recuperar documentación no clasificada en los ficheros. 
guerras civiles, una segunda (definitiva) conquista del mundo indio, ${ }^{1}$ la sustitución de la clase mercantil colonial por el capital inglés, el fusilamiento de un Habsburgo. El éxito de la imagen ruralista de la política latinoamericana no es más que el signo que dejó en la mentalidad colectiva un orden instaurado al fin y al cabo tardíamente, pero con tal fuerza, que surgió precisamente como arquetipo de todo el siglo.

En realidad, los itinerarios del liberalismo latinoamericano aún están por reconstruirse. Es cierto que en el continente, así como en otras áreas también, las manifestaciones rurales políticas en el momento del voto expresan un conjunto de valores y de prácticas inspirados en la deferencia jerárquica y en la reciprocidad asimétrica. No obstante, es preciso recordar, cuando se observa este fenómeno en términos de continuictad, que, a diferencia de la gran propiedad territorial europea, la latinoamericana no se apoya en una sólida tradición de derechos políticoterritoriales autónomos. Por el contrario, durante toda la época colonial los hacendados no gozaron de una condición corporativa propia, como fue el caso de los propietarios de las minas, los comerciantes, los militares, el clero, los indios, los artesanos, etcétera. Todos estos estamentos tampoco tuvieron nunca una representación cameral que de cualquier modo constituyera un precedente para la instalación de la representación liberal. Además, es cierto que el sistema corporativo colonial criollo siempre fue parte integrante del espacio urbano, el único que gozó por tradición y por ley de legitimidad política frente a la corona mediante el cabildo o concejo municipal. ${ }^{2}$ Estas dos circunstancias, olvidadas con demasiada frecuencia, indican que la ruralidad política liberal representó tan sólo una expresión indirecta de la llamada "herencia colonial", cuya continuidad con respecto al liberalismo habría de investigarse, sobre todo en el espacio urbano. Como se ha recordado recientemente, éste nunca tuvo en América Latina un papel weberianamente alternativo para el campo, ${ }^{3}$ lo que hace todavía más complejo el problema: es necesario reconstruir el papel de la dimensión urbana en el nacimiento y desarrollo del liberalismo, procurando no caer ni en el arquetipo weberiano ni en el ruralista.

Aquí se intentará demostrar cómo un espacio urbano mexicano instauró y consolidó el proceso electoral de tipo liberal y cómo en este proceso se afirmaron una serie de prácticas y de valores colectivos respecto al voto que tradicionalmente se consideran como originarios de las áreas rurales. Nuestro análisis pretendería sugerir que, al contrario

1 Carmagnani, Regreso, 1989; Farris, Maya, 1984.

2 Góngora, Estado, 1951, pp. 69-90; García, Estado, 1951, pp. 69-90; García, Ciudad, 1955, vol. l, pp. 283-475; Morse, "Prolegomenon", 1972, pp. 360-394.

3 Carmagnani, "Citta", 1987, pp. 491-512. Fernand Braudel desarrolló interesantes reflexiones comparadas hace 30 ańos en polémica con Otto Brunner en "Conception", 1959, pp. 301-319, ahora en Braudel, Scritti sulla storta, Milán, 1973. 
de los modelos de desarrollo económico del siglo xIX en México, dichas prácticas prosperaron y adquirieron su especificidad ahí donde existía una tradición de jerarquías legítimas, es decir en los espacios urbanos, para luego difundirse en el campo precisamente por su compatibilidad con la sociedad rural. Por último, en vista de que está en discusión el nexo entre "herencia colonial" y liberalismo, nuestra atención se concentrará en 1812, año en que se instauró la Constitución de Cádiz en Nueva España. Se analizará una sola elección en particular, la que se celebró en la ciudad de México el 29 de noviembre para nombrar a los miembros del nuevo concejo municipal constitucional.

Ciertas razones específicas hacen de esta elección un objeto de análisis privilegiado. Fue la primera elección de corte liberal, nombró la representación municipal, ${ }^{4}$ se celebró en un espacio urbano fragmentado (eclesiástico, indio y burocrático) que hizo crisis. ${ }^{5}$ Sus resultados y sus prácticas causaron una investigación judicial que se prolongó hasta abril del siguiente año. La voluminosa documentación de archivo sobre esta elección, probablemente única en su género, permite identificar ciertas rupturas con el modelo gaditano en el terreno de la soberanía y de la representación que habrian de acompañar después al liberalismo mexicano durante buena parte del siglo.

Es preciso partir de este último punto, el de la soberanía. La Constitución de Cádiz había tomado el sistema electoral de la Carta francesa de 1791: el voto indirecto de segundo grado para las Cortes y de primer grado para los municipios. La investigación judicial se activó después de la designación de los electores, suspendiendo su reunión por el nombramiento del consejo. Según el intendente provincial Gutiérrez del Mazo, el voto "popular" había marcado el "triunfo de los americanos contrarios a la autoridad real". ${ }^{6}$ Esta afirmación es menos

${ }^{4}$ Los liberales de Cádiz nunca se definieron como demócratas que estaban por designar a los autores del voto directo. El carácter casi universal masculino de los requisitos de la carta gaditana fue aceptado bajo las presiones de la parte de la Asamblea compuesta por sacerdotes con rentas bajas, quienes corrían el riesgo de ser excluidos por la adopción del modelo de empadronamiento. Además, legitimistas y liberales también estuvieron de acuerdo sobre este punto para garantizar el voto a los empleados civiles, a los militares, magistrados $y$ comerciantes. En cuanto al voto para los analfabetos, ello represento una delegación temporal: en 1830 la ciudadanía habría estado reservada a los alfabetos únicamente, Diario, 1870, vol. vil, 23-26 de septiembre y 27-29 de septiembre de 1811, pp. 415-439.

5 Estas elecciones fueron estudiadas en 1946 por Benson, "Contested", 1946, pp. 337 350 con una atribucion errada. Benson las confundio de hecho con las que se celebraron para designar a los representantes mexicanos a las Cortes de España, que tuvieron lugar efectivamente pocos meses despues y cuyos documentos se encuentran en parte mezclados con los que nos interesan. El estado del Archivo General de la Nación ( $A G N$ ), en esa época explica probablemente este error cometido por una investigadora conocida.

6 "Carta reservada del intendente Ramón Gutiérrez del Mazo al virrey Francisco Xavier Venegas", ciudad de México, 2 diciembre 1812, AGN, Historia: t. 398, exp. 5. 
obvia de lo que podría parecer. La Constitución había establecido el derecho de ciudadanía y por consiguiente de voto para todos los nacidos o residentes en los dos hemisferios (arts. 18 y 113); por lo tanto, también los peninsulares, es decir los nacidos en España, podían votar el 29 de noviembre. El punto es que su número era reducido, aproximadamente 2118 hombres adultos en la ciudad de México, frente a 21000 criollos y 11000 indios, según el cálculo de Humboldt basado en el censo de 1793.7 Pero sobre todo la actitud de los patricios criollos - de los moderados que dos años antes no habían apoyado la insurrección y la revuelta de Hidalgono era en absoluto desconocida para las autoridades: el año anterior el general Calleja, entonces comandante en jefe de las fuerzas antirrebeldes, había escrito al virrey Venegas:

Este reino pesa demasiado sobre una metrópoli que vacila. Los criollos, pero también los propios europeos, están más que convencidos de las ventajas de un gobierno independiente y si esta absurda insurrección de Hidalgo hubiera favorecido este sentimiento no habría encontrado mucha oposición. ${ }^{8}$

Resulta dificil imaginar que las autoridades esperaran un resultado que les fuera favorable en las elecciones. Lo que la Audiencia señaló como peligroso fue la obra de seducción de los votantes por parte de muchos personajes anónimos, cuyo papel no estaba previsto por la ley. ${ }^{9}$ Por el momento no interesa el fenómeno en sí, sino su significado en un contexto como el mexicano, donde la nueva Constitución redefinió el conflicto histórico entre la tradición criolla y el Estado.

\section{JERARQUÍA Y SOBERANÍA EN LA TRADICIÓN CRIOLLA}

La paradoja del 29 de noviembre, tal como quedó clara en la propia investigación judicial, consistió en que una elección que habría debido consolidar el Estado terminó por negarlo, y permitió que los notables criollos conquistaran, no sólo el control sobre el cabildo, que ya detentaban, sino, sobre todo, el espacio urbano. La práctica electoral articuló el modelo de soberanía tradicional criolla con el nuevo modelo de representación liberal. Esta distinta referencia de los principios de soberanía y de representación fue resultado de las tensiones pluriseculares

\footnotetext{
7 Humboldt, Ensayo, 1966, pp. 128-130.

8 "Carta reservada del brigadier Félix María Calleja al virrey Francisco Xavier Venegas", Valladolid, 29 enero $1811, \Lambda G N$, Historia: t. 326, exp. 4 .

9 "Dictamen de la Audiencia al virrey...", México, 8 enero 1811 , AGN, Historia: $t$. 447,
} f. 74 . 


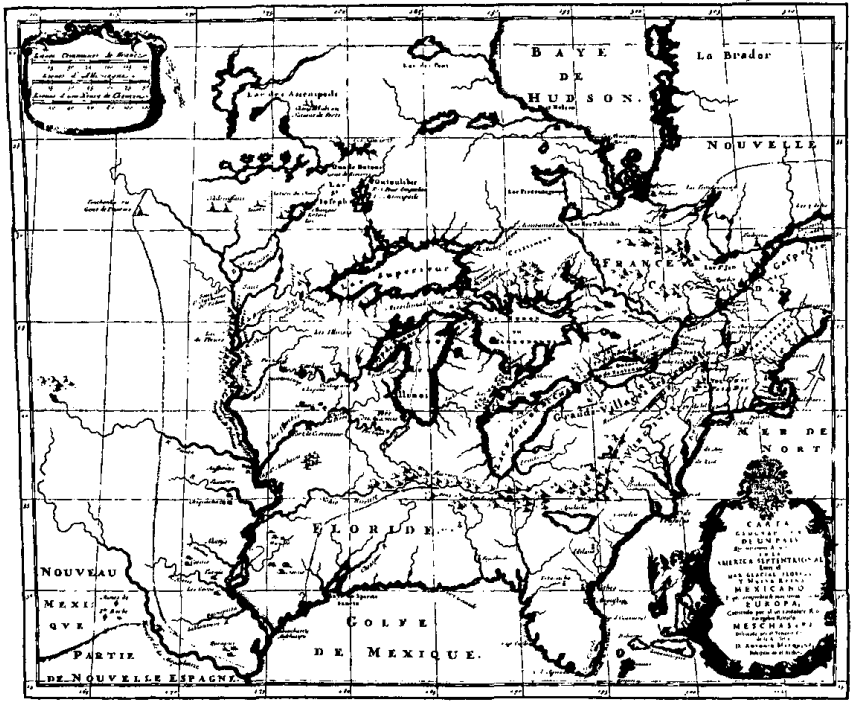

del orden colonial. La historiografía hace tiempo que ha abandonado la imagen de una sociedad colonial dominada por una clase de españoles en perjuicio total de los nativos, pero se ha atenido, en los procesos de desarrollo, a un poder criollo capaz de limitar la evolución del Estado absoluto, ${ }^{10}$ a tal grado, que se habla de "tradición criolla" como de un conjunto de prácticas y de valores de tipo consuetudinario y con gran frecuencia informal.

La naturaleza de estos procesos no es un aspecto secundario de nuestro tema: se trata de identificar el campo de encuentro entre la. tradición política de los criollos y el liberalismo de Cádiz, tal como aparece en las elecciones de 1812. Es conocido que, en 1808, los criollos reaccionaron a la abdicación de la corona frente a Napoleón constituyendo, en las principales ciudades de América Latina, juntas de notables que reivindicaron una soberanía propia, un modelo que la historiografía considera "residual" de la cultura escolástica del siglo XVI, y que pronto fue supuestamente superado por el gaditano. ${ }^{11} \mathrm{Sin}$ embargo,

10 Para una reseña crítica sobre el argumento, véase Muro Romero, "Administración", 1987 , t. 2., pp. 448-454.

II En italiano Oddone, "Independenza", 1976, pp. 218-269. 
era muy distinta la opinión de la investigación judicial de 1812-1813, la cual, tras la "seducción" de los votantes, vio con mucha claridad la pérdida del papel de las autoridades, la negación del poder burocrático sobre el espacio urbano que la Constitución les había confirmado como heredera del centralismo borbónico. También es significativo que las autoridades percibieran este problema inmediatamente después de votar los electores, es decir a mitad del proceso electoral, y que no fueron éstos los sometidos a investigación según sus tendencias políticas, sino la modalidad del voto, la homogeneidad de los comportamientos colectivos y las técnicas de movilización empleadas por los criollos. Todo eso era lo que diferenciaba a la sociedad del Estado en un terreno que aparecía ambiguo ante los ojos de la burocracia y por lo tanto sospechoso: el del antiguo orden comunitario criollo entremezclado con el nuevo, establecido por la Constitución.

Esta doble cara del proceso electoral, bien esbozado por la investigación, es un signo de la continuidad de los lenguajes de 1808 que al menos atenúa la impresión de su carácter "residual". Las incertidumbres de la historiografía están además confirmadas por su subevaluación de otro momento que prueba el renacimiento de los espacios urbanos: en 1809 , la Suprema Junta Central española que gobernaba el imperio, decidió reconocer a todas las provincias de ultramar la categoría de "reinos", restableciendo la antigua posición paritaria con la metrópoli de la época de los Habsburgo y acabando definitivamente con el proyecto borbónico "colonial". La Junta admitió entre los propios miembros un representante por cada uno de los virreinatos (Río de la Plata, Nueva Granada, Nueva España, Perú) y por cada capitanía general (Chile, Cuba, Puerto Rico, Guatemala, Venezuela). La política de la Junta fue débil y sin duda de signo conservador, ${ }^{12}$ aunque no es de subestimarse su papel en la convocatoria a las Cortes de Cádiz. ${ }^{13}$ No obstante, se ofrece otro juicio si se mira a los asuntos americanos: el reconocimiento del estatus de "reinos" reinstauró el derecho de representación de las ciudades dentro del imperio y prefiguró el escenario de Cádiz. La representación minoritaria concedida a los americanos los impulsó a éstos a reivindicar una soberanía no delegable, propia de la tradición criolla y de la cual los representantes tenían los mismos requisitos, incluso formales.

Deténgamonos en el representante mexicano Lardizával y Uribe. Éste había sido electo por el cabildo de la ciudad de México en cuanto cabecera del reino, pero su cargo lo ponía al servicio de todas las demás cabeceras de provincia y, a través de éstas, de todos los territorios de Nueva España. Lo muestran las instrucciones enviadas por todas las ciudades, con solicitudes detalladas de pedir reformas y con la recomendación de

12 Rodríguez, Experimento, 1984, pp. 56-58.

13 Artola, Origenes, 1959, pp. 211-234. 
hacer valer el nuevo estatus de paridad. ${ }^{14}$ Con el mismo procedimiento, $y$ con "instrucciones", fueron elegidos los delegados americanos en Cádiz, con la diferencia de que en la Constituyente representaron directamente a las provincias. Las instrucciones indican que, tanto los representantes en la Junta como en las Cortes, actuaron como procuradores de ciudadterritorio, es decir con un mandato imperativo y vinculante y según un antiguo modelo de representación ibérica que en las Indias había asumido otras formas. Ya que no hubo nunca cortes en la colonia, los procuradores se reunían en juntas para decidir sobre el "bienestar general" en caso de vacatio legis del Consejo de Indias. Al igual que en los lenguajes de 1808, también aquí nos enfrentamos con el problema de evaluar el sentido de esta reaparición de antiguas formas político-institucionales. Parece que, después de la conquista, estas juntas decayeron por la consolidación de la burocracia real, aun cuando un estudio de Herbert Prestley de 1921 sostiene lo contrario, citando el caso de Nueva España, donde se habrían llevado a cabo unas cuarenta de tales juntas en el transcurso del siglo XVII. ${ }^{15}$ Incluso teniendo en cuenta que después de tantos años estos datos deben volverse a verificar, persiste el hecho de que, en las rediciones oficiales de las Leyes de Indias (1680), estos derechos a la representación ciudadanoterritorial se mantuvieron y con ellos el privilegio de los criollos a no someterse a leyes que atentaran contra el derecho mancomunal de los pueblos. ${ }^{16}$

Las instrucciones a los procuradores en 1809 y 1810-1812 son así expresión de una idea de soberanía territorial que en la propia legislación colonial es autónoma de la corona. Por otra parte, las investigaciones de los últimos quince años no permiten pensar que se trate de simples residuos de una tradición extinta. La crónica crisis financiera de la corona y la venalidad en el otorgamiento de los cargos indianos permitieron a los criollos conquistar una posición dominannte no sólo en los cabildos, sino incluso en las audiencias. ${ }^{17}$ De este modo adquiere un significado totalmente distinto la secular polémica de los criollos sobre los repartos de las magistraturas, y con ella la propia práctica de la desobediencia de las leyes provenientes de España, fenómenos sobre los que en el pasado ironizó mucha historiografia que vio en ellos una

14 "Instrucciones que, en cumplimiento de la Real Orden de 22 de enero del presente año de 1809 , librada por la Suprema Junta Central depositaria interina de la autoridad Soberana, dirigen los ayuntamientos de la Nueva España al Excmo. Señor don Miguel de Lardizával y Urive, diputado representante por esta Nueva España y vocal de esta Suprema Junta, AGN, Historia: t. 447, exp. $323,179,118,323,358$.

15 Prestley, Municipalidades, 1921, p. 15.

16 Góngora, Estado, 1951, p. 235.

17 Sobre todo, Burkholder y Chandler, Impotence, 1977, han reconstruido las carreras de los miembros de todas las audiencias entre los siglos xuı y xvir. Para una reflexión actualizada del problema, véase Pietschmann, "Burocracia", 1983, pp. 11.37. 
"histórica" propensión de los criollos al empleo público. Se trata por el contrario de signos de un ascenso político criollo que se interrumpe sólo en la segunda mitad del siglo XVIII a consecuencia de las reformas borbónicas y que además remite a una "constitución material" no sólo practicada sino también legitimada jurídicamente.

La revaluación del siglo xvil ya iniciada por Octavio Paz con sus estudios sobre Sor Juana Inés de la Cruz, se convierte entonces en una etapa necesaria para reconstruir la naturaleza de una tradición criolla incluso en un terreno más directamente político, y para entender cómo tal tradición enfrentó y confrontó el desafío neocentralista y neoburocrático de la Constitución de Cádiz.

Es en el siglo XVII cuando se afirma la idea de una "soberanía compartida" entre Estado y comunidad urbana. Con respecto al clásico modelo dual rex/regnun reformulado por los teólogos de la contrarreforma española ${ }^{18} \mathrm{el}$ modelo criollo se distingue en que sostiene que la soberanía no está en el cuerpo "popular" indistinto sino en su representación en el cabildo. Un siglo antes, el español Francisco de Vitoria había afirmado que "el origen de la ciudad y de las repúblicas no es una creación del hombre sino de la naturaleza". Sobre esta idea de naturaleza culta, positiva, que se contrapondrá a la de Hobbes y a la de Rousseau (y que merecería un estudio aparte), Juan de Pereira Solórzano teorizó en 1647 que los "cabildos representan el poder depositado en el pueblo" y por tanto son órganos soberanos ante el rey. ${ }^{19}$ La noción de "comunidad política" como un conjunto orgánico de hombres unidos por vínculos morales y que tienden a un objetivo común se identifica en el siglo XVII criollo con el cabildo, ya que éste, como sostiene Solórzano, "tiene un derecho electoral desconocido para las demás instituciones". 20

En definitiva, la cultura criolla barroca explicitó el significado ambivalente de república. J. Antonio Maravall ha demostrado cómo, en el Siglo de Oro español, este concepto comprendía una comunidad jerárquica de individuos, estamentos y dignatarios, no absorbible por el Estado. ${ }^{21}$ Pero Estado y comunidad seguían siendo parte siempre de una misma república y ello hacía sumamente ambiguos los límites entre autonomía y soberanía de uno con respecto a la otra. Solórzano distingue por el contrario entre repúblicas (las ciudades) y república (el Estado): la libertad

18 Morse, "Heritage", 1964, pp. 124-130.

19 Pereira Solórzano, Politica, (1647) 1930, t. I. p. 69.

20 Obviamente, Solórzano no considera aquí los procedimientos electorales de las corporaciones porque no se trata de "instituciones políticas". Recuerda además que esta legitimidad del cabildo vale también para los cabitdos de los indios, en los cuales los procedimientos electorales estaban estrechamente entrelazados con las jerarquías internas, como lo ha demostrado recientemente Carmagnani, "Cittá", 1987.

21 Maravall, Pbilosopbie, 1965, p. 87. 
de las primeras garantiza el orden de la segunda. ${ }^{22}$ Esta formulación permitió a Solórzano hablar ya sea de repúblicas de indios o de repúblicas de españoles, es decir incluir dentro del modelo de soberanía repartida la articulación, asimétrica pero complementaria, del segmento indio con el blanco, y la cual regía a la sociedad colonial. ${ }^{23}$

El mismo fenómeno de la "corrupción" puede ubicarse en el que fue posiblemente su verdadero terreno, la lucha entre grupos por el control de las riquezas indias, como en su momento sugirió sin mucho éxito van Kalveren. ${ }^{24}$ Como la "seducción" del 29 de noviembre de 1812 , la corrupción colonial se identificaría, más que con un fenómeno "objetivo" o "degenerativo", simplemente con el punto de vista de sectores "burocráticos" peninsulares en retroceso, o de cualquier modo incapaces de afirmar unilateralmente su propio poder frente al criollo. Adquiere entonces un sentido positivo la intuición totalmente olvidada de Mario Góngora:

La práctica de la desobediencia de las leyes tuvo en América un marcado sentido político, y lejos de representar un síntoma de desprecio por la ley, fue la manifestación más evidente del culto a un orden jurídico al cual se sometía el propio monarca. ${ }^{25}$

Es indicativo a este propósito que, en el siglo del ascenso criollo, ya no se presente al rey la petición de tener cortes indianas, como se hizo varias veces en el siglo XVI, sino que se intensifique la polémica sobre los oficios. ${ }^{26}$ Este eclipse de la hipótesis camaral, que de todos modos debe verificarse siempre con base en Prestley, hay que relacionarlo con la continuidad del procurador como único elemento de representación de la soberanía criolla. Profundizar este punto permitiría quizás aclarar cómo el rechazo firme de la corona a otorgar derechos feudales jugó un

22 Ibid.

23 Carmagnani, "Cittá", 1987.

24 Kalveren, "Fiskalismus", 1960, vol. 47., pp. 333 y ss, citado en Pietschmann, "Burocracia", 1983, p. 14.

25 Ibid.

26 El material de archivo al respecto es ingente y su estudio consistiría en reconstruir la mentalidad y los intereses vinculados a las expectativas de los oficios. Citamos aquí la famosa representación del cabildo de la ciudad de México al rey del 8 de mayo de 1771 . Ésta aparece dividida en 3 secciones: en la primera se reivindica el derecho a los cargos políticos con base en las Siete partidas de Alfonso X el Sabio del siglo xN (el derecho de los naturales a las magistraturas) y de las Leyes de Indias (4 y 5, tít. 3, libro I). En la segunda se reivindica el derecho al estatus para salvaguardar el honor; en la tercera se defiende de la acusación española de ser incapaces en tanto "indianos" afligidos por el abatimiento a causa del clima, una polémica que nos lleva al gran tema estudiado por Antonello Gerbi en su Disputa, 1983. "La Representación de la ciudad de México hecha a S. M. en el año de 1771, 8 de mayo", Biblioteca Nacional de Madrid (BNM), secc. Manuscritos: III OI, $133 \mathrm{f}$. 
papel clave para que los espacios urbanos adquirieran un peso estratégico en la cultura política criolla. La "ruralidad" de la ciudad colonial, tan frecuentemente subrayada por la historiografia, tiene entonces una doble cara: las haciendas del patriciado criollo-mercantil ${ }^{27}$ pero también la especificidad de las Indias, la imposibilidad de acceder a derechos políticos más allá del espacio urbano. Las propias instrucciones de 1809 y de 18111812 demuestran que los cabildos se consideraban representantes de un orden territorial urbano-rural, de una "polis agro-urbana"28 soberana con respecto al Estado ya fuera absolutista o liberal.

Llegamos así al punto que nos interesa más: la capacidad de subsumir en un único modelo de soberanía no cameral intereses no sólo urbanos y rurales, sino también corporativos y étnicos, constituye una de las manifestaciones específicas de la tensión estamentos-corona en la América Latina colonial. ${ }^{29}$ Aquí encontramos el nexo entre tradición corporativa (la representación de intereses particulares) y soberanía compartida: en el carácter territorial y no administrativo del espacio urbano criollo, que es ante todo una comunidad jerárquica de sujetos colectivos, como lo confirmó en 1808 un miembro del cabildo de la ciudad de México. ${ }^{30}$

Es también cierto que las nuevas prácticas electorales decimonónicas surgieron de las soluciones constitucionales que los diversos liberalismos dieron al problema de la soberanía estatal. La de Cádiz fue centralista y determinó una escisión inmediata entre los nuevos mecanismos de representación electoral que los americanos aceptaron, y la idea de soberanía que rechazaron. Los criollos aceptaron el proyecto de elecciones indirectas de primer grado para los cabildos, y de segundo grado para las cortes porque ellos y los liberales españoles eran antidemócratas, es decir antijacobinos. Cuando se ha observado el encuentro de América Latina con la "modernidad" política en la coyuntura de crisis del sistema colonial, siempre se ha omitido colocar en su justo relieve el rechazo universal del

27 Ibid.

28 Morse, "Prolegomenon", 1972, p. 369. Algunas instrucciones se encuentran en el Archivo de las Cortes de Madrid: "Instrucciones para la constitución fundamental de la monarquía espańola y su gobierno [...] dada por el M.I. Ayuntamiento de la ciudad de Guatemala a su diputado el señor Don Antonio de Larrazábal", Archivo del Congreso de los Diputados (Ultramar): leg. 32. exp. It.

29 Pueden encontrarse reflexiones estimulantes sobre el tema de la fractura clases/monarquía en Koenigsberger, "Parlamenti", 1986, pp. 9-26.

30 En ese año el cabildo intento reactivar y fracasó por un golpe de la Audiencia, el mecanismo de las juntas de la ciudad. La Audiencia afirmó, y la historiografia ha retomado esta versión, que el cabildo era "revolucionario" porque quería Estados Generales como en Francia. Y la única junta que se realizo fue la de los cuerpos políticos de la ciudad de México, en el transcurso de la cual un miembro de la Audiencia le preguntó a Primo Verdad quién era el pueblo. Y la respuesta fue que el pueblo eran las autoridades constituidas, "Junta General celebrada en México el 9 de agosto de 1808", Archivo Historico de la Ciudad de México (AHCM), Historia general: vol. 2254, núm. 34. 
modelo jacobino por la parte americana, no sólo como es obvio en el ámbito del patriciado, sino también en el de las clases medias y populares.

Obviamente la representación indirecta correspondía más al orden jerárquico y "natural" de la tradición criolla y fue retomada por varias constituciones latinoamericanas del siglo XIX; pero cabe recordar que en México la encontramos incluso en el campo de los insurgentes Hidalgo y Morelos, como lo prueba la Constitución de Apatzingán del 22 de octubre de $1814 .{ }^{31}$ En su texto encontramos también un adverbio que dividió profundamente a los liberales españoles y a los criollos en Cádiz, cuando se discutió el problema de las fuentes de la soberanía: ésta era "esencialmente" de la nación para los primeros, y "originalmente" para los segundos. Toda la sesión del 28 de agosto de 1811 se ocupó de este asunto y no por casualidad. ${ }^{32}$ Los dos adverbios coagulaban dos conceptos distintos de la soberanía y de sus relaciones con la representación. Al

31 Decreto constitucional para la libertad de la Anérica mexicana, sancionado en Apatzingín a 22 de octubre de 1814, tít. "Formas de gobierno", cap. v "De las juntas electorales de parroquia", cap. Iv "De las juntas electorales de provincia", en Tena Ramírez, Leves, 1957.

32 Diario, 1870, vol. II, núm. 330, pp. 1714-1717.

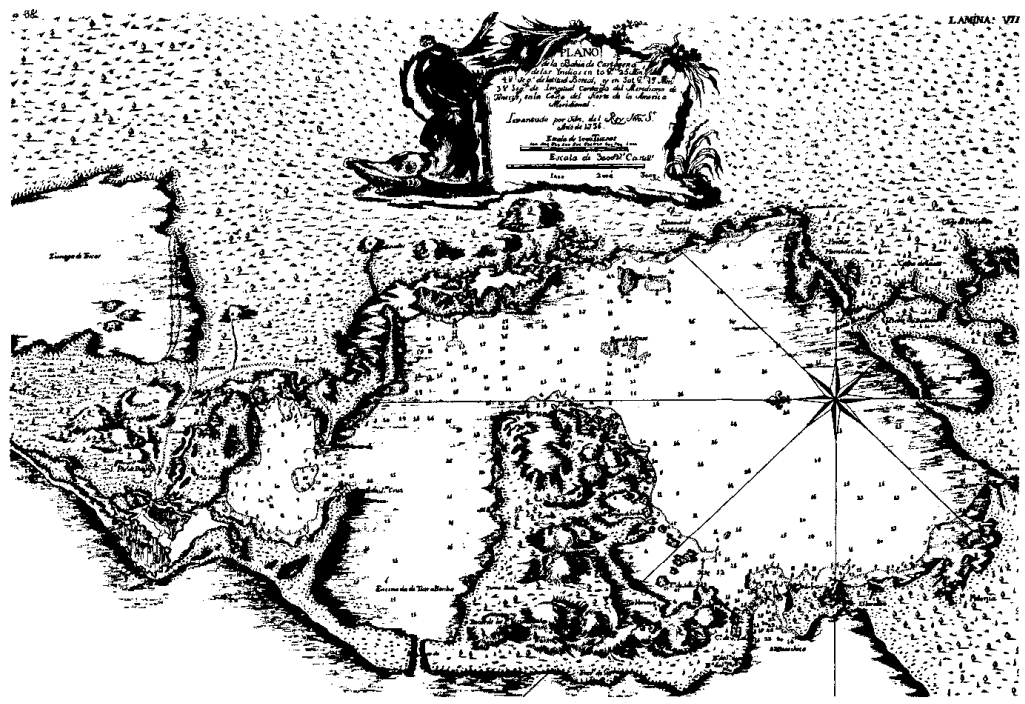


famoso adverbio de Sieyès, los americanos contrapusieron una idea de soberanía "originaria" por ser preestatal, que permitía a una nación elegir un gobierno pero también separarse de él, porque "la forma de gobierno no es esencial a la nación". ${ }^{33} \mathrm{La}$ nación para los americanos era un conjunto de cuerpos políticos naturales, es decir cabildos y territorios, mientras que el Estado era un cuerpo artificial porque era producto de un acuerdo político, de un pacto entre entidades soberanas. La distinción entre nación natural y artificial es fundamental para nuestro tema: a partir de ella y a lo largo del siglo $\mathrm{XIX}$, se definieron dos valores diferentes para procesos electorales formalmente similares: el voto para los ayuntamientos perteneció a la nación "natural" preestatal, mientras que el voto para los congresos expresó el orden "artificial" estatal regulado por pactos. Ya que para los criollos el Estado no era el fundador del orden político, tampoco hay que confundir el problema de la inestabilidad del siglo XIX mexicano con el de una supuesta ilegitimidad de las prácticas políticas.

En Cádiz, la doctrina americana aparece como un conjunto algo incoherente de términos rousseaunianos mezclados con ideas corporativas y jusnaturalistas, pero adquiere una coherencia intrínseca si se la considera por lo que fue: la expresión renovada del modelo urbano-territorial del siglo XVII. La disyuntiva crucial para el futuro fue que, al oponerse al centralismo liberal, los criollos no aceptaron la distinción entre titularidad y ejercicio de la soberanía.

Las consecuencias para los procesos electorales fueron relevantes. La Constitución dibujó tres votos: para las cortes, para las diputaciones provinciales y para los ayuntamientos: pero la naturaleza de cada voto dependía de las funciones asignadas a los tres órganos. Los dos últimos fueron considerados como órganos administrativos de carácter consultivo, presididos por funcionarios del centro y por ende en las Indias por burócratas españoles. Las elecciones para ayuntamientos y diputaciones tenían por objeto ratificar un nuevo orden burocrático a través de la cooptación de los notables criollos, transformados así en funcionarios indirectos con funciones consultivas. ${ }^{34}$ Además del ejercicio de la ciudadanía, y por tanto del voto, la Constitución excluyó a las castas, creando así un motivo ulterior de conflicto porque, para los criollos, las elecciones habrían debido reconstruir a la sociedad "natural"

33 "Representación dirigida a las Cortes por cuatro individuos de la Comisión de Constitución, contra un artículo de ésta", en Diario, 1870, vol. II, p. 5.

34 Este aspecto surgio claramente durante la discusión sobre el artículo 307, que dejaba a los jefes políticos (los ex intendentes) la presidencia de los ayuntamientos. El dipurado liberal español Toreno afirmó sin medias palabras que "las diputaciones provinciales y los ayuntamientos deben considerarse como agentes del poder ejecutivo y no como cuerpos representativos", en ibid., sesión del 10 de enero de 1812, p. 2591. 
y por tanto a la comunidad, como se sostuvo en defensa de las castas, reclamando el derecho sancionado por la legislación de las Indias para convocar cabildos abiertos, es decir asambleas de toda la comunidad. ${ }^{35}$ El cabildo abierto de la tradición colonial se convirtió, por tanto, en el modelo sobre el que implantar el primer nivel del voto, el "popular", de modo que se reintegrasen los notables del segundo nivel a la soberanía "natural", que no admitía distinciones entre la titularidad y su ejercicio. Cádiz fue, entonces, todo menos una superación de la tradición criolla, y el encuentro con el liberalismo sucedió únicamente en el terreno de los nuevos mecanismos de representación, y desde luego no en el de la soberanía.

\section{LA CRISIS DEL ESPACIO URBANO}

Entre los lenguajes criollos de Cádiz y la realidad urbana de la ciudad de México la distancia no era grande: la organización espacial reflejaba una sociedad de grupos y corporaciones con funciones específicas, cada uno de los cuales se movía a la sombra de privilegios e inmunidad en barrios densamente poblados y casi autosuficientes a nivel cotidiano. Más que por la condición económica, en 1812 la residencia se determinaba todavía por los vínculos de parentesco, profesiones, por nexos corporativos y por el origen geográfico y étnico. ${ }^{36}$ La política de los Borbones no había logrado modificar el carácter aglutinante del espacio urbano, ${ }^{37}$ y tampoco la ubicación voluntaria de los grupos, la persistencia y reproducción de los poderes endógenos que la Iglesia (y no el Estado) mediatizaba de tal forma que se conformaban relaciones de complementariedad cultural más que de subordinación. Al fracasar su transformación en agente centralizador del Estado, la ciudad conservó, así, el perfil del siglo xvir, que la recuperación económica del siglo XVII había fortalecido y no empañado. ${ }^{38}$ La reforma de los cabildos, que quiso Carlos III, ${ }^{39}$ fue acompañada

35 El 4 de enero una Representación de los americanos replicó que "con base en nuestras leyes corresponde a los ayuntamientos el pleno gobierno económico de las provincias". El día anterior el diputado mexicano Guridi y Alcocer había afimado que "la naturaleza del cabildo abierto es corporativa y testa es la base de su autonomía, en ibid., p. 2618.

36 Es cuanto se extrae de los estudios de Dolores Morales, "Estructura", 1976, pp. 363 402. Cón el mismo título la autora ha publicado una versión más elaborada de este análisis del empadronamiento de 1813, en Moreno Toscano, Ciudad, 1978 pp. 71-107.

37 Utilizamos aquí el concepto de "agregación" y/o "segregación" en el sentido propuesto por Vance Jr., "Land", 1971, pp. 101-120. Sería agregación cuando la residencia depende de un complejo de normas sociales y culturales (parentesco, profesión, origen geográfico y étnico) más que de la condición económica.

38 Fue Brading, Miners, 1971, quien reconstruyo el ciclo de expansión y de enriquecimiento criollo del final del siglo xvil.

39 Esta reforma colocó a propios y arbitrios, es decir las finanzas municipales, bajo el 
del fortalecimiento de las instituciones sociales criollas (corporaciones, hermandades, cofradías, milicias, etcétera) ${ }^{40}$ En las elecciones de 1812 participó una sociedad corporativa en desarrollo articulada en tres espacios: burocrático, eclesiástico, indio. .

La red urbana se había dividido geométricamente en 1782 en ocho distritos mayores y 32 menores para facilitar el control sobre la población, independientemente de su pertenencia a grupos, corporaciones y etnias. Cada distrito quedó bajo un alcalde, cuyos deberes de "padre político" dibujaron un tipo de intervención dirigida a sustraer el poder disciplinario al monopolio endógeno de los grupos y a transferirlo al Estado. ${ }^{41}$ El nuevo sistema habría debido cooptar al patriciado a la gestión subordinada del espacio político urbano, como pasó con los grandes de España en Madrid, pero los criollos y caciques indios no participaron en ello y los nuevos cargos cayeron en manos de las castas. ${ }^{42}$

Predominaba en la ciudad de México el espacio eclesiástico, cuyas prerrogativas en tema de provisiones y puestos de trabajo eran tales, en palabras de un funcionario español, "como para crear un vínculo muy estrecho con todas las clases que componen el estado". 43 En las parroquias, y por tanto en toda la ciudad, la administración real no podía hacer nada sin la intervención de los prelados y "nadie ignora la mulitud de oficios que la Iglesia pudo llenar a través de los curas, la sacristía, las obras pías, ni los vínculos de parentesco o de otro tipo a que recurrían las principales gentes para dar una carrera a sus hijos y protegidos". ${ }^{44}$ Una investigación reciente nos dice, como confirmación de estas palabras, que en 1811 la Iglesia era propietaria de $47 \%$ de los valores inmobiliarios y de más de la mitad del suelo, todo en la zona interna de la traza donde estaban las avenidas y las calles empedradas. ${ }^{45} \mathrm{La}$ parte más importante de

control de los intendentes. Desde este punto de vista los liberales españoles de Cádiz no hicieron más que constitucionalizar el orden del régimen antiguo. Guillamont, Reformas, 1980. pp. 187 y ss.

40 Carmagnani, "Cittá", 1987, p. 497; Moreno Toscano y Florescano, Sector, 1974, p. 19; Singer, Economia, 1974, p. 8.

${ }^{41}$ Se trataba de vigilar que hubiera maestros y doctores -enviar a los pobres al hospicio y a los enfermos al hospital-; reprimir la vagancia -mandar a los jóvenes a trabajar con "patrones conocidos"-; facilitar a las mujeres trabajo en casa; vigilar las condiciones de la pavimentación - colaborar en la recaudación de los impuestos. Todos los alcaldes mayores y menores habrían tenido el bastón y gozado de fuero criminal y civil. Ordenanza de la nobil/sima ciudad de México en cuarteles, creación de las alcaldias de ellos y regia de su gobierno, dada y mandada observar por el Excmo. señor don Miguel de Mayaga, México, 1782.

42 AHCM, Policía en general: vol. 3627, exp. 43, f. 8.

43 B. Ladrón de Guevara, "Discurso sobre la política de México", en Lombardo de Ruiz, Antologia, 1982, p. 103.

44 Ibid., p. 104.

45 Dolores Morales, "Estructura", 1976, p. 71; el estudio de Lavrin, "Riqueza", 1973, pp. 100 y ss., demuestra que la mitad de la propiedad eclesiástica era de los conventos en 1813 , 
la ciudad era de manos muertas, del clero, y ello hacía al fuero eclesiástico más potente que la burocracia.

Frente a los primeros dos estaba, por último, el espacio indio, formalmente identificable como el de fuera de la traza según el modelo del siglo XVI de las dos repúblicas. ${ }^{46}$ Las dos parcialidades de San Juan Tenochtitlan y Santiago Tlatelolco eran una mezcla de pueblos pre y posthispánicos, organizados espacialmente en barrios y políticamente según la jerarquía india: desde los gobernadores hasta los alcaldes de barrio. De ambas dependía una compleja jerarquía de diversos funcionarios, hasta incluir a algunos pueblos foráneos, aunque Gibson afirma que a finales del siglo XVII las dos parcialidades habían perdido gran parte de sus unidades rurales. ${ }^{47} \mathrm{La}$ traza de 1812 no distinguía físicamente el espacio blanco del indio porque en las parcialidades vivían también blancos, mestizos y castas, ${ }^{48}$ y así también ya no había parroquias indias sino mixtas. ${ }^{49}$ Las leyes hablaban todavía de segregación entre las dos repúblicas para fines eclesiásticos y tributarios, pero en realidad no se hacía nada para separar a los indios de los demás habitantes. A fin de identificar el "verdadero" espacio indio, sería necesario observar los vinculos tributarios, la ubicación de las cajas de comunidad que administraban los bienes étnicos y los cabildos indios. ${ }^{50}$ Sin embargo, en conjunto se puede afirmar que la realidad india de la ciudad de México era muy distinta a la de las áreas rurales: sin calpulli, con una propiedad individual desarrollada de los inmuebles, muy comercializada y predominantemente artesanal y por ello con intercambios más hacia la traza que hacia los pueblos foráneos. ${ }^{51}$ Está además el hecho de que, en 1811 , once de los quince barrios censados presentaban una organización familiar muy ramificada, de modo que se garantizaba la relación con los linajes y el acceso a los cargos políticos y religiosos. ${ }^{52}$

pero que ésta era mínima en el siglo anterior, y que por tanto al menos buena parte de la riqueza inmobiliaria de la Iglesia se habría desarrollado en la época borbónica.

${ }^{46}$ Ia traza era "un plano regulador de la parte de la ciudad [que] estaba destinada a los españoles y en la cual se diseñaron las calles y los aislamientos, y se distribuían las viviendas entre los españoles que se establecían ahí. La traza comprendía un cuadrado relativamente reducido y su límite separaba la ciudad española de la india que se extendía en el exterior" O'Gorman, "Reflexiones", 1960, p. 15; Sartor, Cittá, 1981, pp. 41-46.

47 Gibson, Aztecas, 1967 , pp. 372-412.

48 Brun Martínez, "Razas", 1978, pp. 113-123.

49 En 1772 se habia abolido el esquema anterior de las parroquias territoriales según el esquema de las dos repúblicas y se había instaurado el sistema de las parroquias mixtas, Gibson, Aztecas, 1967.

so El problema es particularmente compiejo porque la ubicación de las cajas no correspondía necesariamente a la localización de los pueblos y barrios, como lo ha demostrado Lira, Comunidades, 1983, Apéndice 3.

s1 Gibson, Aztecas, 1967.

52 Brun Martínez, "Razas", 1978. 
Esta partición triple del espacio político hizo crisis el 29 de noviembre porque su función de articular y mediar entre los poderes disciplinarios difusos fue "usurpada" por el proceso electoral. 53 La nueva representación de tipo liberal permitió a los criollos volverse verdaderamente notables, es decir llenar el hueco entre la fuerza de sus instituciones sociales y la debilidad de las políticas y, así, unificar el espacio urbano. Esta transformación fue posible por el impacto que tuvo la práctica de los requisitos de voto en los vínculos entre los tres espacios urbanos, ya debilitados en los dos años anteriores a las elecciones.

Hasta 1810-1812, el espacio indio se había articulado de hecho con el administrativo mediante el sistema del tributo y de la administración real sobre las cajas. ${ }^{54}$ Las listas de los tributarios se compilaban con base en lo debido a las jerarquías indias, a la Iglesia y al rey. ${ }^{55} \mathrm{La}$ abolición del tributo en 1810 debilitó la relación entre los primeros dos espacios y el tercero porque la nueva articulación, establecida entre cuarteles y barrios, como ya se vio, resultó un fracaso. El problema es entender si hubo un reforzamiento del espacio indio. Tal vez sí, si consideramos que la ordenanza de Cádiz sobre las desamortizaciones de las tierras comunitarias (octubre de 1812) no se aplicó en la ciudad de México sino sólo en los pueblos foráneos y que una parte del mecanismo tributario fue reactivado por las autoridades étnicas. ${ }^{56}$ Esto vale también para las cajas incluso si el problema es más complejo debido a que sus ingresos se depositaban en el Banco Nacional de San Carlos y eran controlados por un funcionario español. ${ }^{57}$ La solución gaditana al problema indio es de todos modos menos obvia de cuanto permite entender el decreto de supresión de las repúblicas porque, por ejemplo, las cajas se conservaron para financiar el proyecto de repartición de las tierras comunitarias a los propios indios. ${ }^{58}$ p. 40 .

53 Véase a proposito de esta categoría weberiana las reflexiones de Abrams, "Cittá", 1983,

54 Borah, Juzgado, 1985, pp. 217.221.

55 La recaudación de impuestos permitía a la administración real identificar, si no todos, por lo menos una parte de los límites de dos parcialidades, y en su interior la ubicación de los barrios. Los registros de los tributarios permitían en definitiva reconstruir la distribución territorial de varios grupos étnicos.

56 Borah, Juzgado, 1985, p. 393.

57 Lira, Comunidades, 1983 , p. 46, observa que entre finales del siglo xvil y los primeros años del $\mathrm{xx}$ los réditos monetarios de las dos parcialidades (tierras dadas en alquiler a españoles y tributos internos) alcanzaron cifras considerables y cita los 20000 pesos de 1785 y 14000 pagados por el administrador en 1807 para la consolidación de la deuda estatal.

${ }_{58}$ En 1810 un decreto de la Regencia previó la distribución de las tierras entre los indios a título individual, según una idea que pertenecía ya a las reformas borbónicas y que después fue retomada por un decreto de la Constituyente de Cádiz en octubre de 1812 y transmitida por real orden en Nueva España en noviembre. González Obregón, Constitución, 1912-1913, vol. I, p. iii. 


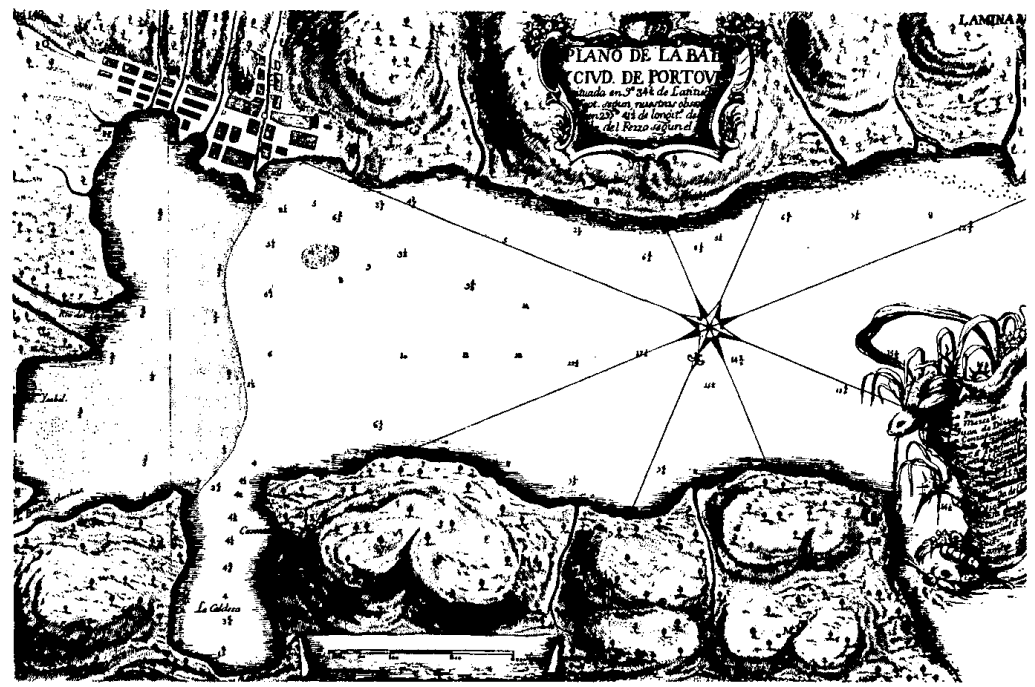

Además, con la Constitución de Cádiz una parte de estas tierras pasaba bajo la administración de los nuevos ayuntamientos electivos puestos formalmente bajo control de los nuevos jefes políticos. Éstos podían aparecer todavía como instancia política superior para los asuntos indios después de la supresión del Juzgado General de Indios. Entre 1812 y 1813 no era de ningún modo obvio que el traslado de los bienes étnicos a los nuevos cabildos implicara la pérdida automática del control por parte de las dos parcialidades. ${ }^{59}$

Es muy probable que haya habido una interpretación india de la Constitución para defender el poder étnico; indicios de ello son la reactivación parcial del tributo, es decir de la relación con el espacio administrativo y la participación en las elecciones del 29 de noviembre para vincularse con el nuevo espacio municipal y criollo. El éxito de

59 Lira, Conunidades, 1983 , p. 23, cita un ejemplo de la percepción india del problema y es de algún año posterior. El 19 de julio de 1820 las autoridades de Santiago Tlaltelolco se dirigieron al "virrey" (aunque con la nueva Constitución éste ya no era tal, sino sólo jefe superior) afirmando que "si bien con el nuevo sistema la parcialidad ha sido interceptada siempre permanecen los naturales que la componen y que conservan todos sus bienes para realizar todos sus cometidos, con la única diferencia de que primero eran colocados bajo la inspección de Su Excelencia y después bajo la de la Junta Provisional". 
Plano 1. El espacio administrativo español: Los cuarteles

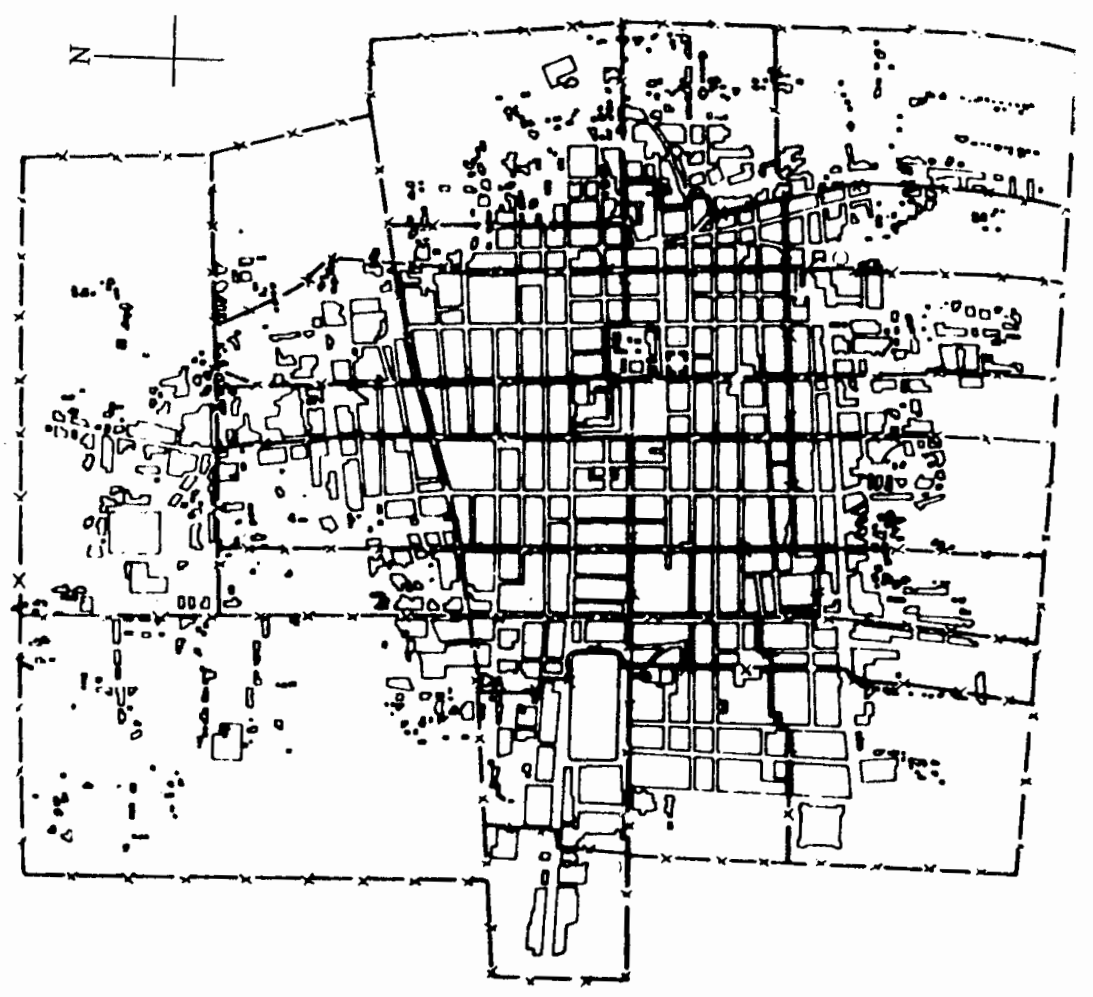




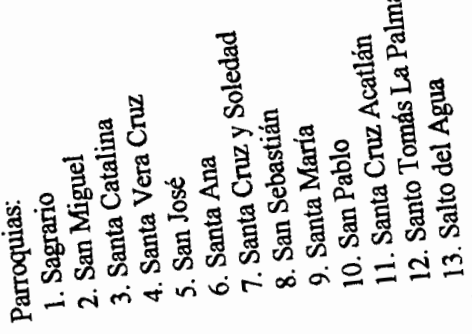

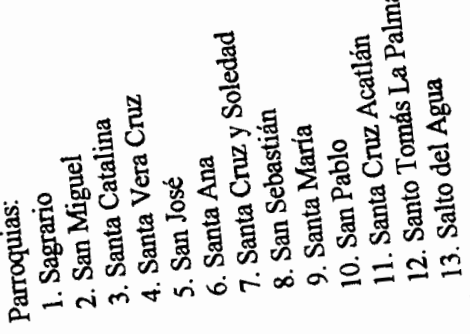
过
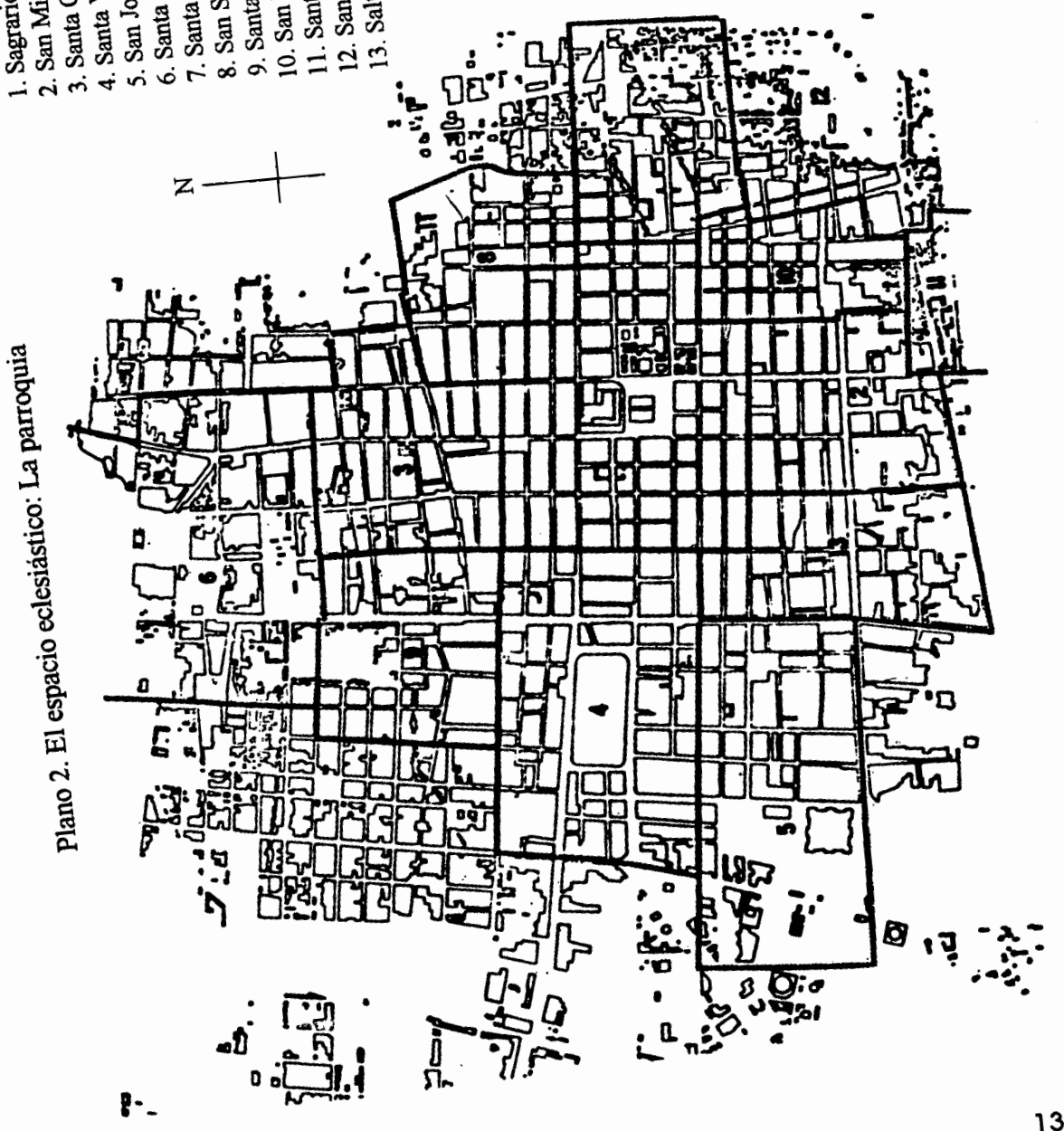

PRÁCTICAS CRIOLLAS Y LIBERAUISMO 


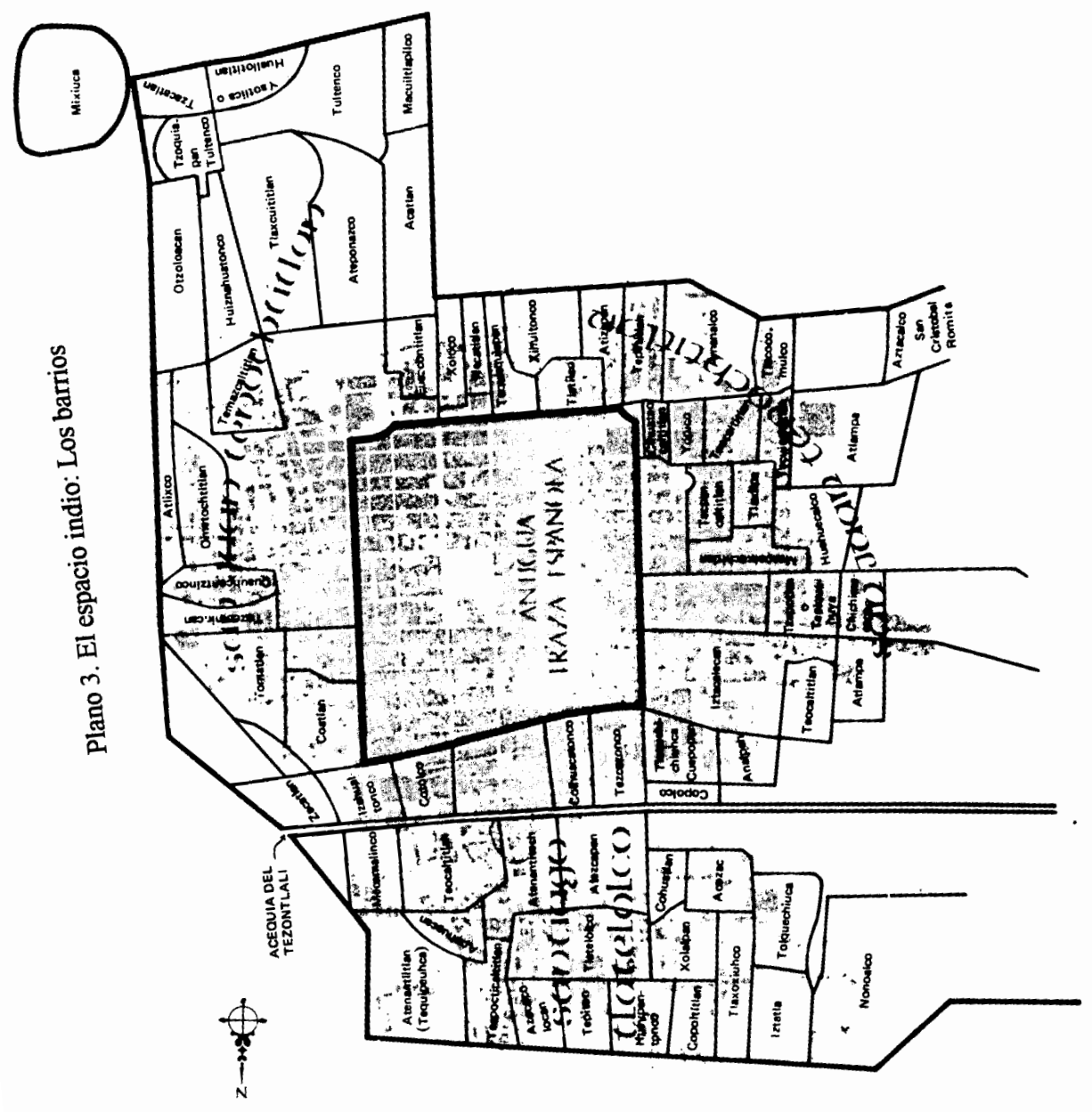

ANTONIO ANNINO 
esta estrategia habría dependido de los nuevos equilibrios políticos institucionales, lo que no era en absoluto obvio el día anterior al voto. ${ }^{60}$

Todas las vicisitudes constitucionales aparecen en realidad bastante más complejas que el estereotipo actuación/no actuación con el cual se han observado después, incluso porque el propio texto reconoció a menudo una legitimidad implícita en las normas no escritas, con un esprit a la Montesquieu no ajeno en absoluto a los liberales españoles, y que en América jugó a favor de la tradición política criolla. La implantación del proceso electoral y el tipo de participación dependieron en buena medida de ese aspecto. Se podía votar como ciudadano del imperio (ius solis) con excepción de los negros, vagabundos o servidores domésticos. No había ninguna indicación aparente por la edad, a menos de identificar a los ciudadanos avecindados y residentes del artículo 25 con el criterio de "notoriedad" de la tradición hispánica, por la cual se era "ciudadano" (de ciudad) en cuanto vecino, y tal por ser propietario de un inmueble urbano y, por tanto, mayor de edad o de cualquier modo socialmente responsable. Cualquiera que fuera el sentido de esta tradición en 1812, la existencia de un criterio de notoriedad se deduce del hecho de que el voto era constitucionalmente un acto colectivo de las asambleas parroquiales (juntas parroquiales), que tenían la facultad indiscutible de decidir los requisitos de voto: "La misma junta decidirá en el acto lo que le parezca y lo que decidiera se ejecutará sin recurso alguno por esta vez y para este sólo efecto" (art. 50).

La soberanía de estas juntas nos dice que el voto fue considerado un derecho colectivo e individual; que el requisito era una especie de puente tendido entre estas dos dimensiones, y que la Constitución se reconoció como un límite con respecto a la sociedad. A través de las juntas, la definición del cuerpo electoral se demandó a las diversas tradiciones territoriales que constituían el imperio, a la fuerza de los poderes disciplinarios difusos o a su debilidad frente al Estado, a las tensiones entre agregaciones y segregaciones sociales, en suma, a un conjunto de variables y de interdependencias que la Constitución misma no quiso desconocer. De modo que, incluso en una carta tan aparentemente rígida y "larga", el límite entre norma escrita y no escrita se presentaba como un continuum, más como una articulación entre orden antiguo y nuevo que como una ruptura. Yà que las prácticas de los requisitos se ubicaron en este límite histórico más que jurídico, el poder de "usurpación" de las juntas frente a la burocracia dependió exclusivamente del grado de legitimidad que el Estado tenía frente a las elites locales. Por esta razón, en Nueva España las

60 Y quizás ni siquiera después. Fsta disposición administrativa de las tierras indias persistio durante la primera mitad del siglo xx y así tambien las cajas de comunidad, cuyos registros pueden encontrarse en los archivos parroquiales. Pero no sabemos nada sobre su funcionamiento en esta época. 
juntas para la elección de los nuevos municipios fueron más importantes que las destinadas a designar la representación en las cortes, donde los americanos estaban de todos modos en minoría. La investigación judicial sobre los "sucesos notorios" del 29 de noviembre demuestra que las autoridades habían percibido que el peligro no provenía de las opiniones de los elegidos, sino de la práctica de los requisitos en las juntas, porque a través de éstas se recreaba una soberanía de la sociedad criolla que las reformas borbónicas no habían logrado destruir y porque en la ciudad de México tal práctica debilitaba el ya de por sí débil espacio administrativo. En los "sucesos notorios" se refleja así, filtrado apenas por la Constitución, toda la herencia colonial con su tensión plurisecular entre instancia burocrática real e instancia territorial criolla.

El interés que asume la investigación judicial no estriba sólo en los datos que nos ofrece, sino también en las percepciones que nos propone, en la voluntad de la burocracia de identificar una presunta ilegalidad en las prácticas de los requisitos y poder así negar la legitimidad de la soberanía de las juntas. Intentemos reconstruir el pensamiento de la Audiencia. El intendente era el responsable de las elecciones y por tanto las presidía ${ }^{61}$

61 Art. 309 de la Constitución, al cual hace referencia el virrey Venegas al confiar

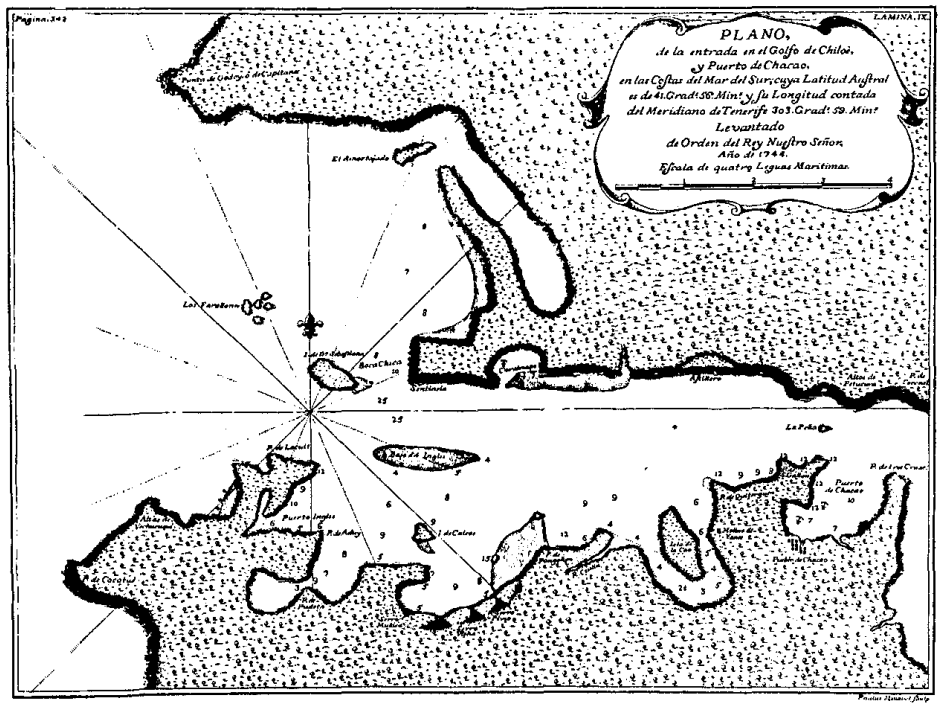


pero ya que se trataba de 13 parroquias, y la del Sagrario incluía casi toda la traza, se decidió que todo miembro del cabildo saliente presidiría una junta, mientras el intendente se reservó la principal, subdividida sin embargo en cuatro mesas. Se trataba de elecciones "administrativas", lo que reforzaba la autoridad del intendente incluso tomando en cuenta que él tenía que presidir el nuevo cabildo electo. No se precisaban normas sobre las funciones del presidente de mesa electoral, salvo la de dirimir conflictos eventuales sobre los requisitos. La posibilidad de ejercer un control sobre las elecciones dependía de los notables que participaban y sobre todo de los curas, quienes eran los únicos que conocían al vecindario. ${ }^{62}$ Después de haber recopilado los testimonios de los presidentes, la Audiencia se encontró de frente con esta situación: tres presidentes de once sostenían "con seguridad" la plena legalidad de las juntas, todos los demás afirmaron confiar en los curas y las autoridades étnicas en caso de duda. ${ }^{63}$ Existía la sospecha de que hubo votos incluso de "hijos de familia" de servidores domésticos, de castas, y de que, en muchos casos, se dieron votos repetidos en distintas parroquias. ${ }^{64}$ ¿Cómo construir un caso específico de ilegalidad de las prácticas de los requisitos? $\mathrm{Ni}$ la Constitución ni los decretos de actuación de las cortes hacían referencia al problema. La Audiencia intentó entonces elaborar una doctrina propia con base en el uso adecuado o inadecuado del espacio físico por parte de las juntas. Si hubo desórdenes y "tumultos" de la plebe, si incluso circularon "papeletas de una misma letra" con los nombres para votar, y si votó quien no tenía derecho, éste fue el razonamiento de la Audiencia, y todo ello quería decir que las juntas no habían asegurado el orden público y por tanto, las prácticas de los requisitos eran ilegales.

Con base en esta hipótesis, la segunda fase de la encuesta entre enero y febrero de 1813 intentó averiguar si en la plaza donde se votó hubo espacio suficiente, si la superficie de los toldos protegió a los presentes del sol, si las sillas para la autoridad fueron en número suficientes, si la obra de secretarios y escribanos no estaba comprometida por la muchedumbre, etcétera, toda una serie de requisitos sobre incomodidad

al intendente del Mazo la organización de las elecciones en la ciudad de México, "De conformidad con los tres fiscales de la Audiencia, el virrey al intendente", México, 31 de octubre de 1812, AGN, Historia: t. 47, exp. 6: "Toca a usía, en el concepto de jefe político de esta capital, convocar y presidir las juntas electorales que han de celebrarse a fin de que se nombren alcaldes, regidores y procuradores síndicos del común para el año de 1813."

62 Por lo denás, este papel fue ratificado unos meses después por una "Real Orden sobre la voz que han de tener los eclesiásticos en las elecciones de ayuntamientos constitucionales", AGN, Ayuntamientos: t. 183, exp. I.

63 "Dictamen de la Audiencia al virrey...", México, 8 enero $1813, A_{G N}$, Historia: t. 447 , f. 74 .

64 Ibid. 
del voto. ${ }^{65}$ Superponiendo al nuevo espacio político de las juntas el viejo espacio hipotético de polícia, la Audiencia intentó reubicar en un campo jurídicamente definible el límite entre norma escrita y no escrita que la Constitución había dejado en manos de la sociedad local. El intento fue un fracaso y el 1 de abril, la propia Audiencia autorizó al virrey a convocar a la tan esperada reunión de los electores para designar a los miembros del nuevo cabildo. ${ }^{66}$

El fracaso de la investigación judicial dependió de dos circunstancias. La primera fue la imposibilidad de verificar a posteriori la consistencia "legal" del cuerpo electoral. En diciembre, la Audiencia había recopilado los 17 libros de las actas y los 31 cuadernos con la lista de los votantes y en enero los curas enviaron los datos sobre sus feligreses. Resultó una población inferior al $40 \%$ de la empadronada el año anterior por medio de los cuarteles. ${ }^{67}$ El cura de Santa Veracruz comunicó que no podía enviar datos porque "la gente se esconde, las casas están cerradas y nadie dice quién habita ahí y aquel que acepta hablar tiene interés en no revelar la conformación de la familia" ${ }^{68}$ Con este comportamiento, los indios buscaban normalmente evadir el tributo; en Santa Veracruz el fenómeno era quizás más fuerte por la presencia de una comunidad no sometida a las autoridades de San Juan Tenochtitlan, debido a que era originaria de las tierras occidentales del valle de México. ${ }^{69}$ Pero incluso las cifras de las parroquias blancas del Sagrario, San Miguel, Santa Cruz, Soledad, y Santa Catalina eran muy distintas del padrón de $1811 .^{70} \mathrm{~A}$ través de los cuarteles se empadronaron incluso millares de léperos y una población

65 Ibid.

66 "Dictamen de la Audiencia al virrey Venegas", México, 1 de abril de 1813, AGN, Historia: $t$. 447 exp. II. El 19 de enero los electores habían escrito al intendente para protestar "nuestros derechos" contra la decision de suspender las elecciones, ibid., exp. 2.

67 En el "Dictamen" del 1 de abril, la Audiencia habla de hecho de cifras inadmisibles. Según un cálculo nuestro, resulta que con base en la información enviada por los clérigos de la población incluida en los registros ascendía a 78572 individuos. El empadronamiento de la recién creada Junta de Policía y Seguridad Pública había calculado 168811 para 1811 que, sin embargo, para el empadronamiento de 1813 efectuado por el recién electo cabildo ascendió a 123907 . La diferencia entre las cifras debería depender del hecho de que, en 1811 , la ciudad fue invadida por varios miles de profugos que huyeron de los insurgentes. En 1815 hubo después una fuerte epidemia en la ciudad que causó más de 20000 muertos. Davis, "Tendencias", 1974, pp. 131-134.

68 "Francisco Torquemada al intendente Gutiérrez del Mazo", 8 de febrero de 1813, AGN, Historia: exp. 37, f. 55.

69 Brun Martínez, "Razas", 1978.

${ }^{70} \mathrm{~A}$ discutir con el cabildo los preparativos para las elecciones, Del Mazo afirmó el 3 de noviembre que la parroquia del Sagrario tenía $\mathbf{8 0} 000$ fieles, de los cuales cerca de la décima parte contaban con derecho al voto, "Actas de cabildo", AA: t. 1812, f. 189. El 15 de enero de 1813, el párroco del Sagrario informo al intendente que los fieles de la parroquia ascendían a 31965 almas, AGN, Historia: exp. 25. 
fluctuante que huía de la guerra de los insurgentes; ${ }^{71}$ pero estos datos no explican una diferencia numérica que expresó dos percepciones distintas del problema: la de los registros parroquiales registraba un sistema de agregación social, no el orden de policía de las autoridades.

La segunda circunstancia fue que, a través de la práctica de los requisitos, se manifestaron los principios fundantes de la sociedad americana. El espacio en torno a la mesa donde se transcribieron los votos con voz y con papeletas se delmitó por un toldo bajo el cual, en sillas y bancos, se recibió a curas, personajes prominentes y autoridades étnicas. Las juntas fueron "populares", pero también representativas de las propias jerarquías "naturales" a las cuales se dejó averiguar los requisitos. Y este doble carácter, popular y "naturalmente" representativo, nos indica que en las juntas electorales se reconstituyó el cabildo abierto de la tradición criolla; y tan es así que uno de los presidentes habló precisamente de cabildo, manifestando la verdadera naturaleza de esas asambleas. ${ }^{72} \mathrm{La}$ investigación judicial demostró así que había un orden, una vez más distinto del que pensaban las autoriclades, que podía coexistir con ciertas manifestaciones "tumultuosas" de la plebe e incluso hacer votar a las castas y a los servidores domésticos, pero que permanecía de todos modos soberano frente a los presidentes, quienes no pudieron más que tomar nota. ${ }^{73}$ Este reconocimiento y la composición de las jerarquías nos dice en suma que, sobre el proceso electoral, se rearticularon las relaciones entre espacio eclesiástico, espacio indio y espacio social criollo, sin la mediación del administrativo. En Santa Maria, frente a la plaza mayor, la mesa se ordenó con tres sillas para el cura, el presidente y el escribano, una banca a la derecha para otros tres eclesiásticos y algunos nobles, otra banca a la izquierda para el "cuerpo principal de la República de indios" y dos bancas de frente para los "más decentes concurrentes". ${ }^{44} \mathrm{Y}$ asi en Santo Tomás, San Pablo, Santa Ana (aquí también el gobernador de Santiago Tlaltelolco), San Antonio las Huertas, Santa Cruz Acatlán. ${ }^{75}$

\footnotetext{
71 Muchos testimonios de la época hablan de varios miles de léperos que vagan por la ciudad; el Discurso sobre la politica de Mtéxico (nota 43) afirma incluso que las 4/5 partes de la población estaban compuestas por léperos. El primer embajador estadunidense afirmó en sus memorias que, inmediatamente después de la independencia, los léperos eran 20000. Poinsett, Notes, 1824. p. 48; Florescano, Precios, 1969, p. 153, considera que, a causa de las crisis agrícolas del último periodo colonial, la mayoría de la población de la capital estaba constituida por léperos.

72 "Francisco de Urrutia al intendente Gutiérrez del Mazo", 13 de enero de 1813, AGN, Historia: exp. 22, f. 40 .

73 Primeras relaciones del $15-17$ de diciembre de 1812 , ibid, exp. 4, ff. 19-47.

74 "Francisco de Urrutia al intendente Gutiérrez del Mazo", 13 de enero de 1813, AGN, Historia: exp. 22, f. 40.

75 Para San Pablo, "Juan Antonio de Cobián al intendente Gutiérrez del Mazo", 13 de enero de 1813; para Santa Ana, "Antonio Méndez Prieto al...", 12 de enero de 1813; para San Anronio de las Huertas, "Agustín del Rivero al...", 18 de enero de 1813, ibid., exp. 17, f. 35; exp. 15, f. 33; exp. 15, f. 31 ; exp. 25. f. 43.
} 
Las diferencias en el orden jerárquico territorial se reflejan incluso en la forma asumida por el voto. La Audiencia quiso saber cuántas papeletas habían circulado; en varios casos resultó que los propios presidentes las habían destruido, pero en conjunto la información recopilada nos permite identificar dos modos distintos de votar y dos tipos de juntas. En las parroquias indias y donde más fuerte resulta ser la presencia de las autoridades étnicas, no circularon papeletas ni se celebró una junta verdadera porque "los indios que votaron se retiraron prontamente", "la mayor parte se retiraban luego que votaban". ${ }^{76}$ En San Antonio las Huertas 184 indios de 458 adultos (según la cifra del párroco) votaron sin una sola papeleta en presencia del propio gobernador. En Santa Ana los votantes fueron 573 de poco más de 1200 adultos, ante el gobernador de Santiago Tlaltelolco. En Santa Cruz Acatlán fue electo el ex gobernador de la parcialidad de San Juan Tenochtitlan Francisco Galicia y se presentaron sólo tres papeletas. En cambio, ninguna en Santo Tomás donde resultó electo Dionisio Cano Moctezuma, otro ex gobernador de San Juan. ${ }^{77}$ A excepción de Santa Ana al norte, que comprendía toda la parcialidad de Santiago Tlaltelolco (18 barrios), las otras parroquias citadas se encuentran al sur-sureste de la ciudad, un área que, según el censo de 1811, resulta densamente habitada por indios "puros" y por linajes étnicos. ${ }^{78}$ Si además confrontamos los poquísimos datos de que por desgracia disponemos sobre la conformación del voto dentro y fuera de la traza, en relación con la población adulta de cada parroquia, se perfila una afluencia más alta porcentualmente en las zonas donde es más fuerte el propio espacio indio. Constituye un indicio interesante si se relaciona con los electos, ex gobernadores y clérigos de la parroquia, porque haría pensar en la existencia de un proceso electoral paralelo, el de los cabildos de indios, que se enlaza con el nuevo Cádiz. Hay que recordar que mientras los cabildos criollos preconstitucionales eran perpetuos y "venales", aquellos indios fueron siempre elegibles. Y por tanto, no es arriesgado pensar que la no permanencia de electores indios en las juntas del 29 de noviembre podía haber dependido incluso del hecho de que las "verdacleras" elecciones se hayan celebrado anterioremente, conforme a la práctica de ese tipo de cabildo. ${ }^{79}$

76 "Agustín del Rivero al..."; "Juan Cervantes y Padilla al...", loc. cit.

77 "Agustín del Rivero al..."; "Antonio Méndez Prieto al..."; "León Ignacio Pico al...", 13 de enero de 1813, ibid., exp. 24, f. 42: "Juan Cervantes y Padilla al...".

78 Brun Martínez, "Razas", 1978.

79 Carmagnani, Regreso, 1989. 
El problema de las candidaturas no había sido afrontado por la Constitución ni por los decretos de actuación ni tampoco por las autoridades de la ciudad de México ${ }^{80}$ Como las prácticas de los requisitos, también las de la candidatura fueron ubicadas por los liberales gaditanos en la frontera histórica entre norma escrita y no escrita, que en la colonia redefinía el conflicto entre burocracia y espacio criollo. El bando de convocatoria de las juntas y una deliberación del cabildo perpetuo permiten interpretar una alusión al principio de la "notoriedad", de modo que los vecinos "puedan encontrar personas que merezcan su confianza para elector". ${ }^{81}$ Los centenares de papeletas de una misma letra que circularon el 29 de noviembre demostraron que hubo una organización clandestina del voto o que, de cualquier modo, no se hizo un llamamiento público a la opinión de los electores. A diferencia de la metrópoli, las logias masónicas se difundieron en Nueva España sólo hasta después de la independencia y, por tanto, el problema de las papeletas, como el de las candidaturas en el curso de los primeros procesos electorales, no está claro.

En la batalla de Tlacotepec del 19 de febrero de 1814, los realistas capturaron copias de 31 cartas que la organización secreta de los Guadalupes había enviado al líder insurgente Morelos. En una del 7 de diciembre de 1812 se afirmaba que "el 29 de noviembre en las 14 parroquias de esta capital nuestros electores han obtenido de 28 a $30 \mathrm{mil}$ votos, con gran desconcierto por parte de todos los peninsulares". ${ }^{82}$ Esta afirmación ha terminado por imponerse en la historiografía a pesar de que algunas razones sugerirían un cauto redimensionamiento, comenzando por las cifras. Los Guadalupes eran independentistas, mientras que el patriciado de la ciudad de México era autonomista; además, sólo cinco de los 25 electores para la Audiencia estuvieron en contacto con los

${ }^{80}$ En el bando de convocatoria de las juntas parroquiales, preparado por el intendente y publicado dos días antes, se informaba simplemente : "Como aplicación del decreto superior del virrey del 17 de este mes convoco con el presente [bando] todos los vecinos de esta capital que se encontraban en el ejercicio de todos los derechos de la ciudadanía a fin de que el 29 de este mes se reúnan en el lugar iniciado abajo de sus respectivas parroquias a las 7 de la mañana con el objetivo de elegir a los electores y con este fin cada uno traerá en mente o por escrito el nombre de la persona a quien otorgará su voto...", "Bando del corregidor intendente de la ciudad de México, dado el 27 de noviembre de 1812", en González Obregón, Constitucion, 1912-1913, t. 1, pp. 226-227.

${ }^{81}$ AHCM, "Actas de cabildo": t. 1812.

82 "La Guadalupe Correspondence se encuentra en la University of Texas Library, Latin American Collection, G-346, y ha sido estudiada por primera vez por Timmons, "Guadalupers", 1950, pp. 453-479. 
insurgentes. ${ }^{83}$. El sentido político de la alianza entre las dos posiciones en la ciudad de México es probablemente más complejo del que se lee en la famosa carta, ya sea por los precedentes de muchos de los nuevos miembros del cabildo electo, ya sea por la dificultad en que se encontraba en 1812 el movimiento insurgente, que un año antes había sido derrotado en una batalla campal a las puertas de la capital. Este episodio había demostrado que la ciudad no quiso unirse a los insurrectos, confirmando el análisis de Calleja, y no hay ninguna razón para pensar que el 29 de noviembre la situación había cambiado. Es muy probable que los Guadalupes hayan apoyado a los criollos de la ciudad de México porque el éxito electoral habria debilitado a las autoridades, y por tanto, habría reforzado todo el frente antiespañol. Hay luego otro aspecto del problema que nos atañe más de cerca: el movimiento de los insurgentes estaba confinado al espacio rural porque éste había sido su origen y no lograba controlar los espacios urbanos. Si bien el campo permitía la sobrevivencia, condenaba también a un lento desgaste político sin enlace con la ciudad. Calleja, que sucedió en marzo de 1813 a Venegas, se dio cuenta e impulsó la difusión de los ayuntamientos constitucionales en las áreas de los insurgentes para así reforzar a los moderados y crear un muro de contención político-institucional contra la subversión rural. ${ }^{84}$

Esta estrategia fue favorecida por el hecho de que en los centros menores hubo una intensa continuidad entre la composición de los viejos cabildos perpetuos y los nuevos. ${ }^{85}$ Por lo tanto, había una competencia por el control sobre los espacios urbanos, ya sea por parte insurgente o bien por la española, que da cuenta del comportamiento de los Guadalupes el 29 de noviembre, más que sus propias carțas a Morelos.

Si se sigue el curso de las papeletas con base en los testimonios de los presidentes de las juntas, se puede constatar que cambió notablemente en relación con la composición étnica y con la ubicación de las parroquias, tanto como para poder clasificarlo en tres formas. La primera es la del "verdaclero" espacio indio donde, como ya se ha insistido, la difusión fue casi nula. Y es muy significativo, en nuestra opinión, que en estas parroquias resultaran electos sólo eclesiásticos y ex gobernadores. ${ }^{86} \mathrm{La}$

83 Por una comunicación reservada por la Audiencia a las Cortes de España citada por Anna, Catda, 1981, p. 132.

8. "La junta de gobierno interino formada en Villahermosa de Tabasco, sobre establecimientos de 10 ayuntamientos de aquella provincia", AGN, Ayuntamientos: t. 183, exp. 2; "El intendente de Oaxaca haciendo algunas consultas sobre elecciones", ibid., exp. 4; "Establecimientos de ayuntamientos constitucionales en la intendencia de Valladolid, $i b i d$., exp. 6 .

85 Cuniff, "Municipal”, 1966, p. 80.

86 Nótese que en Santa Ana, con todos los barrios de Santiago Tlaltelolco y donde se elegía un solo elector, el resultado del voto indio fue a favor del cura de la misma parroquia, Ignacio Sánchez Hidalgo. En San Antonio las Huertas los indios votaron por el conde de Jala, eclesiástico, hijo del célebre conde de Regla. 
segunda es de gran difusión y corresponde a las parroquias de Santa Cruz, La Soledad y San Sebastián en el este, San Miguel y San Pablo en el sur y sureste pero dentro de la traza, Santa María y Santa Veracruz en el oeste. La primera sin barrios indios, la segunda con tres, la tercera sin ellos y la cuarta con otros tres, las últimas dos con cuatro y seis. Además de esta última, que, como se ha visto, era la zona de indios extranjeros, las demás tenían una población "mezclada" y fluctuante, con una notable presencia de castas, mestizos y artesanos libres, es decir individuos no vinculados con las estructuras étnicas $\mathrm{ni}$ con las corporaciones ${ }^{87}$ Resultaron electos un eclesiástico y un abogado en la primera, dos abogados en la segunda, un eclesiástico y un abogado en la tercera, dos eclesiásticos en la cuarta, un eclesiástico en la quinta, un abogado y un eclesiástico en la sexta. La tercera forma de difusión de las papeletas es más bien débil y corresponde a la gran parroquia blanca del Sagrario, que ocupa casi toda la traza, y a las tres parroquias, por la mitad de su interior, de San José, Santa

87 Según González Angulo, Autesanado, 1983, pp. 180 y ss., hay para la última época colonial indicios serios de una crisis progresiva de las corporaciones artesanales de la ciudad de México a causa de la multiplicación de los productores independientes y libres, fenómeno que al parecer las autoridades toleraron.

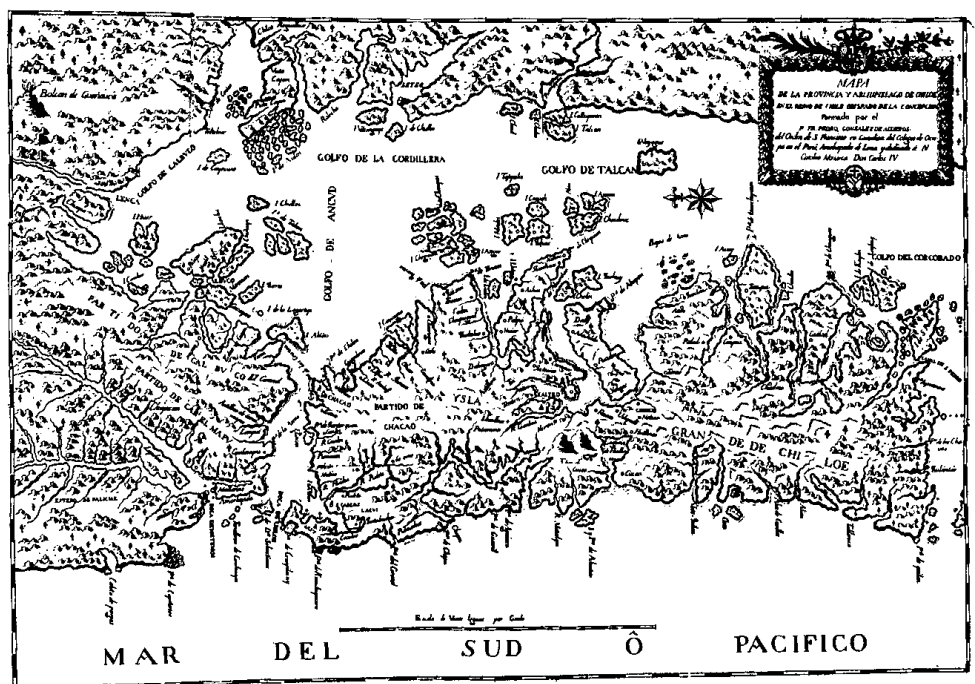


Catalina y Salto del Agua, entre los cuales sólo las últimas dos comprendían barrios indios. La primera, por ser la más populosa, eligió cuatro electores, un canónigo de la catedral y un ex oidor de la Audiencia pero criollo y autonomista, un teólogo y un abogado de una gran familia. Las otras eligieron respectivamente a dos eclesiásticos que ejercían la abogacía, un particular y un militar, un eclesiástico y otro particular. En el Sagrario hubo el mayor número de papeletas que se concentraron no obstante en el ex oidor: 524 de un total de 5892 votos. ${ }^{88}$

Esta clasificación nos dice que los abogados se afirmaron como electores en las zonas de más alta difusión de papeletas y allí donde la población era más fluctuante social y étnicamente. Los eclesiásticos fueron por el contrario electos bastante uniformemente pero más afuera de la traza. En esta última, la composición de los electores es heterogénea y deja entrever una posición social más elevada. El ascenso político a través del proceso electoral del binomio abogados-eclesiásticos resulta vinculado a un espacio social pluriétnico y mestizo no rígidamente "corporativo". Se confirma así una tendencia que encontramos también en el campo de los insurgentes, donde precisamente eclesiásticos y abogados constituyeron los cuadros directivos del movimiento. Estas figuras a menudo se han presentado como una "capa intermedia" de la colonia que, gracias a su crisis y al liberalismo, se afirma como tal. Pero las cifras de Humboldt demuestran que la consistencia de esta "capa" era muy reducida: 517 abogaclos y 171 clérigos seculares (los únicos que podían ser electos) ${ }^{89}$ Es más realista quizás hablar de corporaciones (la de los abogados lo era) que gracias a los procesos electoraes y a las guerras civiles adquirieron un papel y un peso político mucho mayores que su consistencia social.

Otra confirmación de la ubicación de estas figuras corporativas en proceso electoral procede de la investigación individual. Tanto los presidentes como los testimonios directos escuchados por la Junta de Seguridad hablaron casi exclusivamente de "desórdenes", "papeletas", "castas", "gente de pelage miserable" a propósito de las parroquias donde resultaron electos abogados y eclesiásticos. 90 Fue principalmente la parroquia de San Miguel, al sur, la que llamó la atención de las autoridades: los elegidos fueron José Manuel Sartorio y Carlos María de Bustamante, ambos después pasados a los insurgentes. ${ }^{91}$ Aquí hubo un "particlo decidido" a favor de los dos electos, "gente en su mayoría pobre, que no sabía quiénes serían los candidatos pero que decidió votar como

88 "Resumen de las secciones de la parroquia del Sagrario de los votos que sacaron los 4 electores que eligieron los feligreses de ella", $A G \mathrm{~N}$, Historia; t. 447, loc. cit. f. 61 .

89 Humboldt, Ensayo, 1966 , pp. 579

${ }^{90} \mathrm{AGN}$ : loc. cit., exp. 4, ff. 24-35.

91 "Expediente instruido en averiguación del modo con que se procedio al nombramiento de electores en la parroquia de San Miguel", AGN: ya citado, exp. 5. 
votó el del capotito pardo mientras que en otro de capotito blanco los empujaba y un indio cargador distribuía sus papeletas $[\ldots]$ o 3 ó 4 días antes a los dos testimonios se mostró una lista para el Sagrario y para San Sebastián, todos esos nombres resultaron electos". 92 Es indicativo que estas dos candidaturas radicales se hayan presentado en una parroquia entre la traza y los barrios indios bajo el control del poder étnico donde sólo se eligieron eclesiásticos y ex gobernadores. En San Miguel no había barrios indígenas sino mestizos.

La distribución de las candidaturas reflejó la oportunidad ofrecida por unos espacios sociales, territoriales y étnicos bastante autónomos entre sí, lo que permite pensar en acuerdos locales y por ende en una contratación entre Guadalupes y patriciado citadino; en este contexto eclesiásticos y abogados tuvieron un papel bien definido. Esta impresión se refuerza por el resultado final del voto de los electores en abril de 1813. A "pluralidad de votos" fueron electos en orden: once hacendados entre los cuales había tres condes y un marqués (y entre ellos el conde de la Valenciana); cuatro abogados, dos comerciantes, dos ex gobernadores (uno de San Juan y otro de Santiago); un propietario de salchichonería. ${ }^{93}$ Ninguno había sido elector, ni siquiera los dos ex gobernadores indios, y excepto éstos todos los demás habitaban obviamente en el Sagrario. La Constitución no prohibía a los electores ser votados por los concejos municipales y los testimonios recopilados por la Junta de Seguridad hablan de listas con los nombres de los electores, sin hacer referencia a futuros miembros del ayuntamiento, señal de que hubo dos prácticas de las candidaturas, en tiempos y lugares distintos. El proceso electoral indirecto articuló por tanto dos fenómenos: conectó entre sí poderes endógenos difundidos en el territorio urbano y transformó en nuevas jerarquías políticas a las consolidadas jerarquías sociales. El papel o el espacio político concedido a eclesiásticos y abogados fue una indudable novedad en el contexto colonial, pero encontró un límite en el predominio de la clase propietaria. La comunidad criolla se reconstituyó en torno a sus valores jerárquicos, ya fuera mediante la práctica de los requisitos en las juntas, ya por medio de las prácticas de la candidatura. Esta constante dualidad entre soberanía formal y soberanía implícita y "natural" de las jerarquías, que el proceso electoral hizo evidente, nos remite a nuestro punto de partida, es decir al papel del espacio urbano, al enlazar la tradición política criolla con la representación liberal.

Esta perspectiva nos permite distinguir entre fenómenos de inclusión y de exclusión al proceso electoral para así identificar los posibles elementos

92 "Declaración de D. José María Galán y D. Pedro Pérez sobre la seducción para el nombramiento de electores", AGN: loc. cit., Indiferente: 702/15.

93 El título de los electores en Alamán, Historia, 1985, vol. 3, apéndice 10. 
de ruptura. La inclusión de los eclesiásticos y de los abogados fue favorecida por una organización política clandestina, pero representó un fenómeno de homologación social. Como bien se ha observado, estas figuras intermedias no constituyen el "tercer estado" que en la Europa del mismo periodo afirma su autonomía mediante los mecanismos de la nueva representación. ${ }^{94}$ Una consistencia numérica escasa y la debilidad económica, además de vínculos de dependencia familiar o clientela (ya sea de la Iglesia o de los propietarios) no hacen de abogados y clérigos una "clase" en América, sino, como se ha dicho, una corporación entre las otras. La exclusión de la poderosa capa mercantil ibérica fue por el contrario una ruptura en la sociedad colonial de la época por las implicaciones incluso estructurales. Esta clase controlaba gran parte del comercio de exportación de Nueva España y a través de la corporación de Cádiz estuvo en relación directa con los liberales españoles. En mayo de 1811 envió a la Regencia una representación para atacar el derecho a la representación criolla con todos los argumentos clásicos sobre la inferioridad americana que desde hace un siglo acompañaban la disputa sobre el nuevo mundo. 95 En noviembre del mismo año, con una carta para la corporación de Cádiz, un agente fue enviado a las Cortes para defender el punto de vista de los comerciantes ${ }^{96} \mathrm{El}$ propio virrey Calleja, antes de la reunión de los electores, buscó la mediación del obispo de la ciudad de México para hacer elegir una representación del Consulado en el nuevo ayuntamiento. ${ }^{97} \mathrm{La}$ aplastante mayoría de los propietarios (los dos comerciantes no eran españoles) fue por tanto una derrota tanto para las autoridades como para la corporación. Incluso después de la independencia continúa el conflicto entre los sectores comercial y terrateniente hasta desembocar en la revolución liberal, de modo que la exclusión de abril de 1813 fue un acontecimiento coyuntural y estructural al mismo tiempo. El hecho tenía que ver con el acceso y el control a los recursos garantizados por el comercio de exportación: la figura del magnate colonial típica reunía en una misma persona la propiedad de la tierra, el comercio a larga distancia e incluso la actividad minera.

El hacendado propietario que no practicaba el comercio no tenía acceso a la circulación monetaria y estaba obligado a endeudarse. Ia independencia demostró que estos desequilibrios podían incluso reproducirse dentro de la sociedad criolla y es desde este punto de vista como el episodio de exclusión de 1813 adquiere un sentido más amplio que va más allá del conflicto entre peninsulares y criollos.

94 Carmagnani, "Cittá", 1987.

95 "Representación del Consulado de México al rey don Fernando VII el 27 de mayo de 1811", Biblioteca Nacional de Madrid, Senz. Manusc., Fondo América: f. 404.

$96 \wedge \mathrm{AN}$, Operaciones de guerra: t. 31, f. 96.

97 Anna, Caída, 1981, p. 35. 


\section{CONCLUSIONES}

Se ha intentado mostrar cómo el encuentro entre la tradición estamental criolla y la representación liberal gaditana transformó el espacio de la ciudad de México. La naturaleza indirecta del voto, las prácticas de los requisitos y las de las candidaturas unieron entre sí ámbitos territoriales, sociales y étnicos dotados de una fuerte autonomía corporativa y los subordinaron a una nueva jerarquía política que no representó más que la homologación de ciertas jerarquías sociales. Este proceso fue favorecido por el hecho de que en las juntas electorales coincidieron la nueva soberanía constitucional de los requisitos y la antigua soberania del cabildo abierto criollo. Arriesgando un cálculo con base en los datos de Humboldt y en los de la investigación oficial, resultaría que el 29 de noviembre de 1812 tuvieron derecho al voto cerca de 19000 personas de una población de 130000 y con un porcentaje de afluencia de $40 \%$, aún más en las parroquias periféricas, y de casi $70 \%$ en la central del Sagrario. ${ }^{98}$ A pesar de la arbitrariedad de nuestros cálculos, es razonable pensar que se experimentó una afluencia irrepetible en los regímenes de empadronamiento que se instauraron después de la independencia, por la nueva ubicación de las prácticas de los requisitos en los procesos electorales. Gracias una vez más a la investigación de las autoridades de la ciudad de México, sabemos ahora que la solución adoptada en buena parte del siglo fue idéntica a la propuesta por el intendente Gutiérrez del Mazo el 3 de noviembre de 1812. La idea era que, para garantizar la "legalidad" del voto, cada votante se presentara con una cédula, en la cual, además de los nombres de las personas elegidas, figurara la firma con la dirección del votante. ${ }^{99}$ La Audiencia objetó justamente que de este modo se restringiría el voto y la ciudadanía sólo a los alfabetizados, lo

98 Las evaluaciones de Humboldt son las únicas que cruzan sexo, edad y etnicidad, obligándonos sin embargo a tener que elegir entre franjas de edad "larga"; o 16 años o 25. Si elegimos los 25, resulta que los hombres ascienden a poco más de 1500 para los españoles, 9700 para los criollos y 5000 para los indios, un toal de 15700 , cifra que sin embargo no toma en cuenta a los mestizos que, a diferencia de las castas, sí tenían derecho a voto, ni a los servidores domésticos que en cambio estaban exluidos. La población masculina adulta de cada una de las tres clases es igual que $1 / 7$ aproximadamente de los respectivos totales, para los cuales si aplicamos el mismo coeficiente a los mestizos (clasificados por Humboldt) tenemos cerca de 3500 individuos, para un total de 4 clases de poco más de 19000 personas con derecho a voto. En el Sagrario únicamente votaron más de 5000 personas; en Santa Cruz, 992; en San José, 868; en Salto del Agua, 466; en Santa Ana, 573; en San Antonio las Huertas, 184. Si aplicamos el coeficiente $1 / 7$ al total de los fieles de cada una de las parroquias con base en las cifras proporcionadas por los clérigos y obtenemos la mayoría en un $40 \%$ para igualarlas tendencialmente a las de Humboldt, que se basan en levantamientos por cuarteles, recabamos precisamente los porcentajes indicados.

99 AHCM, Actas de cabildo: t. 1812. 


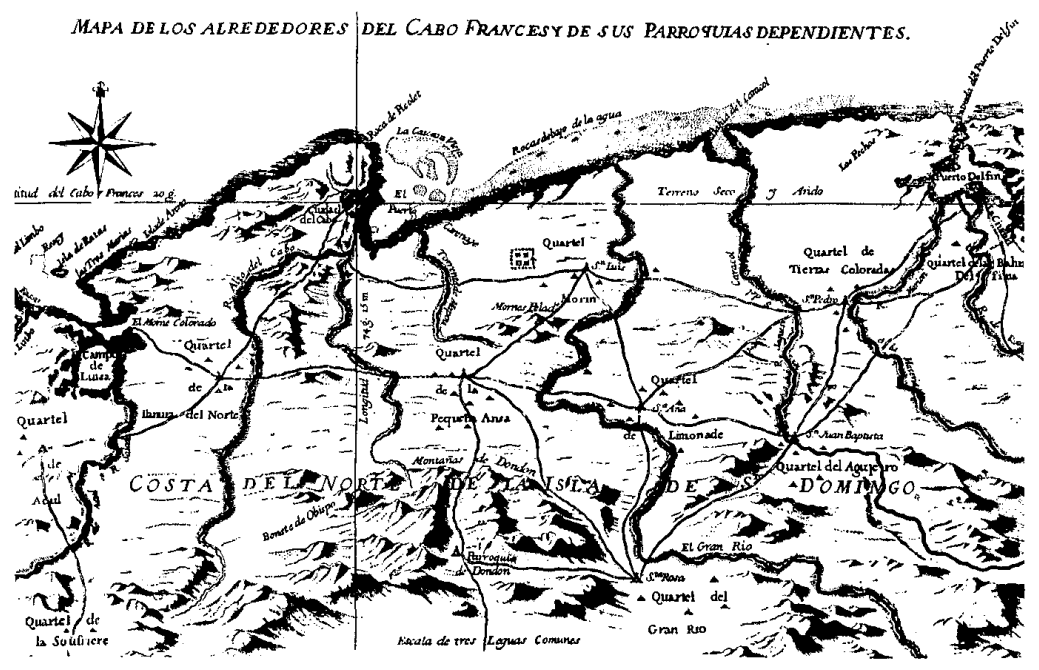

que era anticonstitucional. ${ }^{100}$ Como resulta que esta propuesta no fue nunca publicada, su actuación sucesiva nos muestra una de las lógicas implícitas en el voto publico, que sólo al ser doblemente tal resolvía el problema formal de su legalidad. Hasta la revolución mexicana, el derecho al voto y a la ciudadanía fueron un requisito único $y$, por tanto, la boleta electoral en manos de las autoridades de los ayuntamientos constituyó un doble instrumento de control, porque mediante los patrones electorales se llevó a cabo la lucha contra la vagancia y se instauró una nueva relación entre el espacio rural y el urbano. A lo largo de todo el siglo, las leyes municipales de los estados mexicanos reconocieron a los alcaldes el poder de organizar las elecciones dentro de las haciendas por medio de propios representantes y con el consenso de los propietarios. ${ }^{101}$ Otra consecuencia fue que la mesa electoral y su elección adquirieron una importancia estratégica para la cooptación del electorado, mientras que el 29 de noviembre de 1812 este momento fue irrelevante, como lo muestra el silencio de la investigación judicial.

Sin embargo, el contexto de esta institucionalización de las prácticas

100 "Dictamen de la Audiencia al virrey Venegas", México, 1 de abril de 1813, ^GN, Historia: t. 447 , exp. II.

101 Annino, "Pàto", 1983, pp. 166-169. 
de los requisitos nos dice que la tradición criolla no se atenuó en el tránsito del sistema colonial al de los notables. Los procesos electorales de la primera mitad del siglo XIX mexicano fueron todos indirectos, y a partir de los ayuntamientos. Las elecciones de los notables reprodujeron una compleja red de jerarquías no sólo políticas y sociales sino también de distintas soberanías, que sólo por medio del voto se legitimaban recíprocamente. La experiencia de Cádiz fue frustrante en el propio Cádiz, pero en la ciudad de México y en muchos otros centros, las elecciones usurparon el poder a la burocracia y por ende a la propia asamblea gaditana. La Constitución misma favoreció el proceso, dividida como fue entre su proyecto burocrático y centralizador y la libertad reconocida a todos los centros urbanos, incluidas las localidades con 1000 habitantes o incluso menos, de instituir cabildos clectivos. Ia consecuencia fue que, en México, durante los cuatro años de la Constitución (1812-1814 y 1820-1821), los ayuntamientos clectivos habían pasado de 26 a $484 .{ }^{102}$ El primero y fundamental encuentro entre liberalismo y tradición criolla, se consumó en el terreno de las libertades territoriales y corporativas porque la soberanía criolla había podido afirmarse con las elecciones municipales y no con las de las cortes. Incluso la independencia se había consumado en esta vertiente de la soberanía: todas las principales ciudades y decenas de centros menores se habían opuesto entre junio y agosto de 1821 al proyecto independentista de Iturbide y de su ejército porque, en su primera redacción, el Plan de Iguala no garantizaba ni la Constitución ni la libertad municipal. ${ }^{103}$ En septiembre estas garantías fueron inscritas en

102 "Lista de los ayuntamientos constitucionales de este reino", 30 de febrero de 1821, AGN, Ayuntamientos: t. 120, exp. 2. El incremento mayor se observa en las zonas indias de Puebla y Oaxaca. Éste es un aspecto importante que merecería sin más una profundización, porque parecería confirmar que, como en la ciudad de México, hubo una interpretación india de la Constitución para reforzar el poder étnico mediante la unión entre el Cabildo indio colonial, que, repetimos, era electivo, y el cabildo constitucional. Algunos registros electorales de los pueblos foráneos en torno a la ciudad de México presentan la misma tendencia: se trata de Mixcoac, San Agustín de las Cuevas, Coyoacán. AGN, Operaciones de guerra: t. 364, ff. 459-469.

103 Hemos llegado a esta conclusión con base en dos fuentes. La primera es una obra que cayó en manos de la Junta de Seguridad en abril de 1812, en la cual se describe la ceremonia de juramento del ejército de Iturbide con esta formula: "¿Jura usted frente a Dios y a la cruz de vuestra espada defender la santa religión católica, apostólica y romana? ¿jura usted obediencia a Fernando VII y aceptará y jurará la Constitución emanada de las futuras cortes de esta America septentrional?"

Por lo tanto, es evidente que Iturbide no pensaba mantener en vigor la Constitución de Cádiz: "Acta celebrada en Iguala el primero de mayo y juramento que al día siguiente el señor Iturbide prestó con la oficialidad y tropa de su mando", AGN, Historia: t. 398, exp. 9. La segunda fuente son precisamente las "representaciones" de muchas ciudades entre las que figuran la ciudad de México, Aguascalientes, Querétaro, Puebla, Zacatecas, con las cuales se denunciaba Iturbide porque atentaba contra los derechos constitucionales de la ciudad garantizados por la Constitución de Cádiz, Gaceta de México, marzo de 1821. Los documentos análogos de muchos otros centros menores están en $A \mathrm{GN}$, Operaciones de guerra: t. 19 , ff. 18 y ss. 
la segunda redacción del Plan, lo que demuestra cómo la independencia mexicana fue posible mediante un pacto entre ejército y ciudad.

El régimen de los notables mexicanos nació así de procesos electorales que, por ser implementados en ámbitos corporativos y territoriales, no legitimaron el principio de la separación entre titularidad y ejercicio de la soberanía. La representación de los nuevos ayuntamientos reprodujo el modelo de una soberanía compartida, no delegada, entre poderes territoriales y poderes "centrales". Las relaciones entre estos poderes fueron reguladas por pactos y procesos electorales que sancionaron periódicamente la legitimidad de los contrayentes. Lo que ha generado a posteriori esa imagen de "irracionalidad" de la política mexicana, que tanto éxito ha tenido incluso en la literatura especializada. En realidad, si se distingue entre inestabilidad política y prácticas relacionadas con ella, es posible descubrir un papel de los procesos electorales no secundario para la reproducción de los notables, cuya estabilidad como grupos debería interesar tanto como la de los gobiernos. El hecho de prohibirse a titulares y a funcionarios la soberanía con base en una idea de libertad considerada todavía como un privilegio, era sin duda un principio conflictivo pero no ilegítimo a los ojos de cuantos la personificaron. Hubo a este propósito un lenguaje transversal de la legitimidad de los notables que reunió a liberales y conservadores: el de la nación del Estado natural, con sus jerarquías y soberanías, contrapuesta a la nación constituida de las constituciones escritas y de los congresos. En este sentido, el nexo entre "herencia" colonial y liberalismo no sólo existe, sino que constituye el hecho lindante del régimen mexicano de notables.

\section{Bibliografía}

-Abrams, E. A. Ph., "Cittá e sviluppo economico", en E. A. Abrams y Wrigley, Cittá, storia, societá, Bolonia, 1983.

-Alamán, Lucas, Historia de Méjico desde los primeros movimientos que prepararon su independencia en el año de 1808 basta la época presente, 5 vols., Fondo de Cultura Económica, México, 1985 (facsimilar de la edición de la Imprenta de Lara, México, 1849-1852).

-Anna, T. A., La caída del gobierno español en la ciudad de México, Fondo de Cultura Económica, México, 1981.

-Annino, Antonio, "Il patto e la norma. Alle origini de lla legalitá oligarchica in Messico", Nova Americana, núm S, 1983.

-Artola, M., Los origenes de la España contemporánea, 2 vols., Instituto de Estudios Políticos, Madrid, 1959.

-Benson, N. Lee, "The contested mexican election of 1812", Hispanic American Historical Review, vol. XXVI, núm. 3, agosto 1946, pp. 336-350.

-Borah, Woodrow, El Juzgado General de Indios en la Nueva España, Fondo de Cultura Económica, México, 1985. 
-Brading, David A, Miners and merchants in bourbon Mexico 1763-1810, Londres, 1971.

-Braudel, Fernand, "Sur une conception de l'histoire sociale", Annales. Economies, Sociétes, Civilisations, núm. 2, 1959, pp. 301-319.

-Brun Martínez, G., "Las razas y la familia en la ciudad de México en 1811", en Moreno Toscano, Ciudad, 1978, pp. 113-123.

-Burkholder, M., y D. S. Chandler, From impotence to autbority. The spanish croun and the american audienctas, Columbia, 1977.

-Carmagnani, Marcelo, "La cittá latinoamericana", en P. Rossi (comp.), Modelli di cittá, Turín, 1987, pp. 491-512.

, El regreso de los dioses. El proceso de reconstitución de la identidad étnica en el área de Oaxaca, 1550-1820, Fondo de Cultura Económica, México, 1989.

-Cunniff, Roger L., "Mexican municipal reform, 1810-1822", en Nettie Lee Benson (comp.), Mexico and the spanish Cortes, University of Texas, Austin, 1966, pp. $59-86$

-Davis, K. S., "Tendencias demográficas urbanas durante el siglo XxX en México", en E. C. Calnek y W. Borah, Ensajos sobre el desarrollo urbano en México, SEP, México, 1974 (Sepsetentas, 143).

-Diario de las Cortes Generales y Extraordinarias, Madrid, 1870.

-Farris, N. M., Maya society under colonial rule, the collective enterprise of survival, Princeton, 1984 .

Florescano, Enrique, Precios de/ maiz y crisis agrícolas en México, 1708-1810, El Colegio de México, México, 1969.

-García, J. A., "La ciudad indiana", en Obras completas, 2 vols., Buenos Aires, 1955.

-Gerbi, Antonello, Disputa del Nuovo Mondo, Nápoles, 1983 (1955). [La disputa del Nuevo Mundo. Historia de una polémica, 1750-1900, Fondo de Cultura Económica, México, 1982].

-Góngora, M., El Estado en el dejecho indiano, época de fundación, Santiago de Chile, 1951.

-González Angulo, Jorge, Artesanado y ciudad a finales del siglo XVII, FCESEP, México, 1983 (Sep 80).

-González Obregón, Luis, La Constitución de 1812 en Nueva España, 2 vols., México, 1912-1913.

-Gibson, Charles, Los aztecas bajo el dominio español, 1519-1810, Siglo XXI Editores, México, 1967.

-Guillamonte, J., Las reformas de la administración local durante el reinado de Carlos III, Madrid, 1980.

-Humboldt, Alejandro de, Ensayo politico sobre el reino de la Nueva España, Porrúa, México, 1966 (Sepan cuantos..., 39).

-Kalveren, J. van, "Fiskalismus, Merkantilismus, Korruption. Drei Aspekte der Finanz und Wirtschaftspolitik währen des Ancien Régimen", en Vierteljabrscbrift fïr Sozial und Wirtschaftsgeschichte, Wiesbaden, 1960, vol. 47.

-Koenigsberger, H. G., "I parlamenti in Europa e in Italia nell étá moderna", en

C. Carini (comp.), La appresentanza nelle istituziont e nelle dottrine politicbe, Florencia, 1986. 
-Lavrin, Asunción, "La riqueza de los conventos de monjas en Nueva España: estructura y evolución durante el siglo xvII", Cabiers d'Amerique Latine, núm. 2, 1973.

Lombardo de Ruiz, Sonia, Antología de textos sobre la ciudad de México en el periodo de la Ilustración (1788-1792), INAH, México, 1982 (Colección Científica, 113).

-Maravall, José Antonio, La pbilosopbie politique spagnole au xvie siècle dans ses rapports avec l'esprit de la ContraReforme, París, 1965.

-Morales, Ma. Dolores, "Estructura urbana y distribución de la propiedad en la ciudad de México en 1813", Historia Mexicana, vol. xxv, núm. 3 (99), enero-marzo 1976, pp. 363-402.

-Moreno Toscano, Alejandra y Enrique Florescano, El sector externo y la onganización especial regional de México (1521-1910), INAH, México, 1974 (Cuadernos de Trabajo, 1).

-Moreno Toscano, Alejandra, Ciudad de México, ensayo de construcción de una bistoria, INAH, México, 1978 (Colección Científica, 63).

-Morse, R., "A prolegomenon to latin american urban history", Hispanic American Historical Revieu, vol. LII, núm. 3, agosto 1972, pp. 359-394.

- . - _ - "The heritage of Latin America", en L. Hartz. The founding of new society, Nueva York, 1964.

-Muro Romero, F., "Administración y sociedad en la América española hasta 1750", en Antonio Annino et. al (comp.), América Latina: dallo stato coloniale allo stato nazione (1750-1940), Actas del VII Congreso de la Asociación de Latinoamericanistas Europeos, 2 vols., Florencia, 1985, Milán, 1987.

-O'Gorman, Edmundo, "Reflexiones sobre la distribución urbana colonial de la ciudad de México", en Seis estudios de tema mexicano, Universidad Veracruzana, Jalapa, 1960.

-Oddone, J., "Dall independenza all'organizzazione nazionale", en Charles Gibson, J. Oddone y Marcelo Carmagnani, LAmerica Latina, Turín, 1976, pp. 218 269.

-Percica Solórzano, José de, Política indiana, 5 vols., Madrid-Buenos Aires, 1930 (primera edición, 1647).

-Pietschamnn, Horst, "Burocracia y corrupción en Hispanoamérica colonial. Una aproximación tentativa", Nova Americana, núm. 5, 1983, pp. 11-37.

-Poinsett, Joel R., Notes on Mexico, made in autumm of 1822 by a citizen of the United States, Filadelfia, 1824.

-Piestley, H. I., Municipalidades coloniales españolas, México, 1921.

-Rodríguez, Mavio, El experimento de Cádiz en Centroamérica, 1808-1826, Fondo de Cultura Económica, México, 1984.

-Sartor, M., La cittá e la conquista. Mappe e documenti sulla trasformazione urbana e tervitoriale nell'America centrale del 500 , Roma, 1981.

-Singer, P., Economía política del urbantsmo, México, 1974.

-Tena Ramírez, Fernando, Leyes fundamentales de México, México, 1975.

-Timmons, W. H., "Los Guadalupes: a secret society in mexican revolution for independence", Hispanic American Historical Review, vol. xxx, núm. 4, noviembre 1950 , pp. 453-479.

-Vance Jr., J. A., "Land-assingment in the precapitalist, capitalist and postcapitalist city", Economic Geography, 1971, vol. xı.VI, pp. 101-120. 